\title{
Utilization of Biowaste-derived Catalyst for Biodiesel Production: Process Optimization Using Response Surface Methodology and Particle Swarm Optimization Method
}

\author{
Ikbal Bahar Laskar, ${ }^{\mathrm{a}}$ Tuhin Deshmukhya, ${ }^{\mathrm{b}}$ Aayushi Biswas, ${ }^{\mathrm{c}}$ Bappi Paul, \\ Bishwajit Changmai, ${ }^{c}$ Rajat Gupta, ${ }^{d}$ and Sushovan Chatterjee ${ }^{\mathrm{e}}$ and Samuel \\ Lalthazuala Rokhum ${ }^{\mathrm{c}, \mathrm{f}}$
}

${ }^{a}$ Department of Mechanical Engineering, National Institute of Technology Silchar, Assam788010, India

${ }^{b}$ Department of Mechanical Engineering, Madanapalle Institute of Technology and Science, Madanapalle-517325, Chittoor District, Andhra Pradesh, India

'Department of Chemistry, National Institute of Technology Silchar, Assam-788010, India. ${ }^{\mathrm{d} D e p a r t m e n t ~ o f ~ M e c h a n i c a l ~ E n g i n e e r i n g, ~ N a t i o n a l ~ I n s t i t u t e ~ o f ~ T e c h n o l o g y ~ M i z o r a m, ~ A i z a w l-~}$ 796012

${ }^{\mathrm{e} D e p a r t m e n t ~ o f ~ M e c h a n i c a l ~ E n g i n e e r i n g, ~ C o o c h ~ B e h a r ~ G o v e r n m e n t ~ E n g i n e e r i n g ~ C o l l e g e, ~}$ Cooch Behar, West Bengal, India.

${ }^{\mathrm{f}}$ Department of Chemistry, University of Cambridge, Lensfield Road, Cambridge CB2 1EW, UK.

Corresponding author email: 1r512@ cam.ac.uk and/or rokhum@che.nits.ac.in; Tel.: +91

3842 242915; Fax: +91 3842-224797

\begin{abstract}
In this experimental and optimization study, banana (Musa acuminata) flower petals ash has been considered as an effective catalyst in the room temperature $\left(28{ }^{\circ} \mathrm{C}\right)$ assisted transesterification to produce biodiesel from waste cooking oil (WCO). The transformation of Musa acuminata flower petals to ash catalyst has been performed by simple conventional open-air burning process. Three important parameters (catalyst concentration, methanol/oil (M/O) molar ratio and time) that play significant role in conversion of WCO to waste cooking methyl ester (WCME) were investigated. In order to maximize the conversion rate these key transesterification parameters were optimized using central composite rotatable design (CCRD) of response surface methodology (RSM). A metaheuristic algorithm
\end{abstract}


popularly known as Particle swarm algorithm (PSO) has been used to observe a clear picture of the global optimum points scattered around the search domain. PSO has also been used to validate the results obtained from CCRD. The chemical composition and morphology of ash catalyst has been investigated using several analytical techniques such as X-Ray Diffraction (XRD), Fourier Transformation Infrared Spectroscopy (FTIR), X-Ray Fluorescence Spectroscopy (XRF), X-ray Photoelectron Spectroscopy (XPS), Thermal Gravimetric Analysis (TGA), Energy Dispersive Spectroscopy (EDS), Brunauer-Emmett-Teller (BET), Scanning Electron Microscope (SEM), Transmission Electron Microscope (TEM) and Hammett Indicator method. It was observed that the catalyst remained active till $4^{\text {th }}$ reaction cycle. The catalyst's reusability, renewability and robust activity in the reaction makes it efficient, economic, green and industrially applicable.

Keywords: Biodiesel, heterogeneous catalysis, Musa acuminata flower petals, Central Composite Design, renewable energy, sustainability

\section{Graphical Abstract}

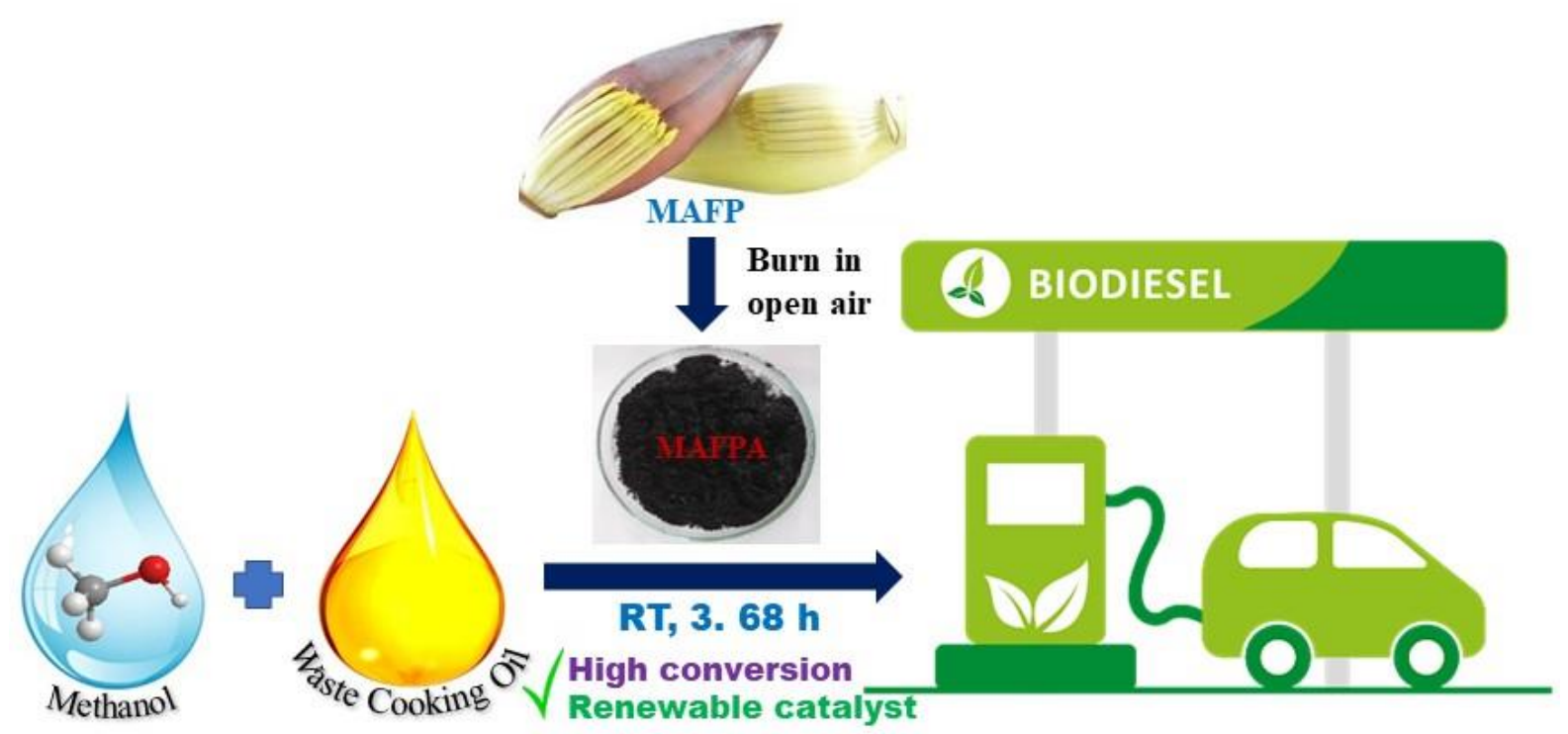

\section{Introduction}

The rapid industrial growth coupled with uncontrolled population explosion has resulted in an over dependence on the fossil fuel which is fast depleting and resulted in alarming global 
warming in recent years. Thus keeping in mind the current scenario, the need to discover environment friendly and renewable source of fuel has been felt around the globe at present (Betiku and Ajala, 2014; Kouzu and Hidaka, 2012). In the light of this, biodiesel which is non-toxic, biodegradable as well as renewable has attracted wide spread attention (Shibasakikitakawa et al., 2007). Though biodiesel production is an expensive compared to fossil fuels, but this factor can be nullified by using low cost feedstock like non-edible (SathyaSelvabala et al., 2011) and waste oils (Guan et al., 2009). Usually by using vegetable oils the total cost of production becomes approximately twice the cost of fossil fuels wherein $60-75 \%$ of cost involvement accounts for usage of vegetable oil (Canakci and Sanli, 2008; Piker et al., 2016). Apart from this, the acute shortage of land for cultivation of edible vegetable is a big hindrance in commercializing edible vegetable oil-based biodiesel (Gui et al., 2008). Thus, waste cooking oil (WCO) (Kulkarni and Dalai, 2006) which can serve as an alternative to vegetable oil in terms of availability and environment friendliness can be used as a cheap feedstock for low cost production of biodiesel.

Of late, the heterogeneous catalysts have gained attention due to their low cost of production compared to their homogeneous counterparts. Most importantly, the problems (expensive catalyst separation process, high wastewater generation during washing, saponification, non-reusable and additional reactant utilization) encountered with the homogeneous catalyst has made the researchers shift their focus to heterogeneous catalysts. Moreover, heterogeneous catalysts owing to their reusability and less corrosive nature have become a favorable choice in biodiesel production (Balbaşi et al., 2011). The catalysts derived from rice husk (Chen et al., 2015), Banana peduncle (Balajii and Niju, 2020), banana peel (Betiku et al., 2016), Brassica nigra plant (Nath et al., 2019), trunk of Musa balbisiana Colla (Deka and Basumatary, 2011), tucuma peels (Mendonça et al., 2019) and Lemna perpusilla (Chouhan and Sarma, 2013) are some of the biomass waste-based solid catalysts that have been successfully used in the last few years. The outcome of some of these transesterification studies showed that the calcined ash samples of biomass can be used directly as heterogeneous solid catalysts without chemical modification. Balajii and Niju has managed to achieve a FAME yield of 98.69 wt.\% using Napoleon's plume seed oil and calcined Banana peduncle ash (Balajii and Niju, 2020). In another study, Nath et al. obtained 98.87 wt.\% FAME yield using soybean oil and Brassica nigra plant ash (Nath et al., 2019). Deka et al. considered yellow oleander seed oil and trunk of Musa balbisiana Colla for FAME production where a yield of 96 wt.\% has been recorded (Deka and Basumatary, 2011). In order to counteract the high price linked with the use of vegetable oil as feedstock, 
various studies have been carried out to convert WCO into biodiesel using biomass based solid catalysts. These studies have reported the synthesis of various catalysts for conversion of WCO such as oil palm ash (Chin et al., 2009), lipase (enzyme) (Babaki et al., 2017), egg shells (Singh and Verma, 2019), chicken and fish bones (Tan et al., 2019), chicken bones (Farooq and Ramli, 2015), waste ostrich-egg shells (Tan et al., 2015), eggshell and peat clay (Putra et al., 2018), chicken manure (Jung et al., 2018) and white bivalve clam shell (Niju et al., 2016). Tan et al. managed to obtain $89.5 \%$ biodiesel yield with chicken and fish bones as catalyst from WCO at $65^{\circ} \mathrm{C}$ (Tan et al., 2019). In another study, Farooq et al. transformed WCO to biodiesel $(89.33 \%)$ with chicken bone at temperature of $65{ }^{\circ} \mathrm{C}$ for $4 \mathrm{~h}$ using 15:1 methanol to oil (M/O) molar ratio and 5 wt.\% catalyst loading (Putra et al., 2018). Jung et al. used chicken manure as catalyst to achieve a biodiesel yield of $95 \%$ from WCO with the expense of $350{ }^{\circ} \mathrm{C}$ (Jung et al., 2018). Though these catalysts can successfully convert WCO to WCME, but an elevated temperature of $60-100{ }^{\circ} \mathrm{C}$ is needed for completion of the reaction which demands high end facilities like condensers attached with chiller, heater and temperature controller machine to name a few. This complex system which also demands tremendous amount of energy to run raises the biodiesel cost in return. In order to reduce the cost associated with temperature assisted biodiesel production approach, Piker et al. managed to produce biodiesel from WCO at room temperature. Though a high biodiesel yield of $97 \%$ was achieved with 6:1 M/O molar ratio, it took $11 \mathrm{~h}$ for the reaction to complete (Piker et al., 2016). In this current study, one of the major objectives is to reduce the conversion time of WCO to biodiesel using biomass-based catalyst.

Banana the second largest produced fruits in the world (Mohapatra et al., 2010) has a great potential in the yield of biodiesel. With a record global production of 101,992,743 MT in 2012, Africa alone accounted for a massive 15,863,068 MT (Betiku et al., 2016). Petals of banana flower automatically peel out as the fruit grow and generate biowaste. Thus, disposal of peels and petals of banana waste have become a matter of concern for the countries where the production is high. Though catalysts derived from banana peel (Betiku et al., 2016), banana trunk (Deka and Basumatary, 2011) and banana peduncles (Balajii and Niju, 2020) have already been studied in biodiesel production, the application of banana flower petals as a catalyst in transesterification reaction to produced biodiesel has not been reported in the literatures.

The conventional catalysts with micropores structure poses some inherent difficulties in converting large and viscous feedstocks (plant or algal oil) to biodiesel whereas the mesoporous and macroporous catalysts have seen to perform reasonably well (Wang et al., 
2019). Lee et al. carried out an extensive review on several solid acid and base catalyst's surface properties and pore architectures (Lee and Wilson, 2015). The study found that the catalyst carrying pores structures interlinking using meso- and macro-porous channels obtained immense improvement on reaction rate due to its capability of diffusion of the reactants in the pores which increase the biodiesel production rate. They also reported that micropore structure possessing catalysts showed lower active in the transesterification reaction due to the lack of active sites accessibility in the pores (Lee and Wilson, 2015). Carrero et al. [31] plant a secondary mesoporous structure on the microporous H- $\beta$-zeolite to improve the diffusion of reactants into the pores to enhance esterification of microalgal oil (Carrero et al., 2011). Thus, the mass transfer limitation of the reactants could be enhanced by improving the diffusion properties using the presented catalyst.

Several critical factors are responsible for the production of biodiesel. The parameters such as M/O molar ratio, catalyst loading, reaction temperature, and reaction time are some of the key variables that directly influence the yield. Optimizing these parameters thus becomes crucial in improving the efficiency of the biodiesel production (Dharma et al., 2016) - Response surface methodology (RSM) is a powerful tool frequently employed by researchers to design experiments and record the effects of the variables on the final response. RSM has so far been used in numerous studies related to biodiesel to optimize its production (Balajii and Niju, 2020; Mendonça et al., 2019; Singh and Verma, 2019; Tan et al., 2019). Betiku et al. produced biodiesel from neem oil where they optimized the production process using RSM and artificial neural networks (ANN) where a yield of $99.1 \%$ and $98.7 \%$ is obtained respectively by these two methods (Betiku and Ajala, 2014). Balajii et al. used central composite design (CCD) of RSM to optimize the two-step biodiesel production process parameters where $\mathrm{CCD}$ applied in transesterification and predicted biodiesel yield of $99.36 \%$. Under the condition determined by CCD, biodiesel yield of 98.69 $\%$ was quantified experimentally (Balajii and Niju, 2020). Several studies related to optimization of biodiesel production from banana peel (Betiku et al., 2016), eggshell (Singh and Verma, 2019), chicken and fish bones (Tan et al., 2019) have been investigated using CCD.

By considering the fact that huge amount of waste is generated from banana flower petals along with banana peels due to the high consumption of this fruit worldwide, this study aims to convert waste (Musa acuminata flower petals (MAFP)) into a novel catalyst by simple conventional burning method. Our continuous effort on transforming biowaste into a valuable product as low-cost, renewable and biodegradable catalysts in various organic 
transformations (Rajkumari et al., 2019) (Pathak et al., 2019) as well as in transesterification reactions (Changmai et al., 2019; Laskar et al., 2018a; Pathak et al., 2018; ) (Changmai et al., 2019b) has directed us towards the investigation of Musa acuminata flower petals ash (MAFPA) as catalyst for converting WCO to WCME. In order to optimize the reaction parameters (i.e catalyst loading, $\mathrm{M} / \mathrm{O}$ ratio and reaction time) experimental runs were designed with central composited rotatable design (CCRD) of RSM. A powerful swarmbased metaheuristic optimization technique, particle swarm optimization (PSO) has been used to perform a proper global optimization of important variables in order to improve the biodiesel yield. As per the authors knowledge, this is the first ever application of any swarm based algorithm in the area of biodiesel research. Application of swarm intelligence in this area can help scientists and researchers to gain an insight about the optimum design variables that helps in improving yield by properly digging out global optimum points in the domain.

\section{Experimental}

\subsection{Materials}

WCO, collected from two distinct hotels of Silchar, Assam, India, contains some food debris and moisture which were removed by filtration through filter paper followed by heating at $120{ }^{\circ} \mathrm{C}$. The properties of treated WCO were determined by ASTM methods which are listed in Table 9. Musa acuminata flowers were fetched from the local market of Fakirtilla, Silchar to collect unused large petals for further use. Bromothymol blue $(\mathrm{pKa}=7.2)$, phenolphthalein $(\mathrm{pKa}=9.8)$, indigo carmine $(\mathrm{pKa}=12.2), 2$,4-dinitroaniline $(\mathrm{pKa}=15.0) 4$-nitroaniline $(\mathrm{pKa}$ =18.4), methanol and acetone were purchased from Sigma Aldrich. The acid value of WCO and biodiesel was determined by a standard titration method using phenolphthalein indicator (Rajkumari and Rokhum, 2020) where it is seen that the percentage of free fatty acid (FFA) is $0.98 \%$. Since the acid content is less than $2 \%$ pre-esterification is not needed. $\mathrm{CDCl}_{3}(\mathrm{D}$, $99.8 \%$, cat. no. DLM-7-100S, which was used as a solvent in nuclear magnetic resonance (NMR) analysis) was purchased from CIL Inc., USA. Methyl hexanoate (analytical standard, $>99.8 \%$, cat. no. 21599, used as an analytical standard for gas chromatography-mass spectroscopy (GC-MS) analysis) was procured from Sigma-Aldrich.

\subsection{Catalyst preparation and characterization}


Large petals of Musa acuminata were separated from the fruits. The petals were then thoroughly washed with distilled water and sundried. Subsequently the dried petals were burnt in air and grounded to fine powder. The physicochemical property of the prepared ash was then determined using the following analyses which include XRD, XRF, IR, XPS, TGA, TEM, SEM, EDX, $\mathrm{CO}_{2}$-TPD and BET. X-ray diffraction (XRD) study of waste banana flower petals (BFP) was carried out on a Bruker AXS D8-Advance powder X-ray diffractometer with the following parameter setting- $\mathrm{Cu}-\mathrm{K} \alpha$ radiation( $\mathrm{K}$-Alpha1 wavelength ,$\lambda=1.54056 \AA$ and K-Alpha2 wavelength , $\lambda=1.54439 \AA$ ), $35 \mathrm{~mA}$ current, $40 \mathrm{kV}$ generator voltage, $2 \theta$ in range $15^{\circ}-90^{\circ}$ at a scanning rate of $2 \% \mathrm{~min}$. The catalyst elemental analysis was performed on Bruker S4 Explorer X-ray Fluorescence (XRF) spectrophotometer. FTIR analysis was done to determine the functional group of the catalyst and IR spectra was obtained on 3000 Hyperion FTIR spectrometers (Bruker, Germany) within range from 400$4000 \mathrm{~cm}-1$. The catalyst surface element and binding energy of the corresponding elements were identified by XPS analysis in a Thermo Fischer Scientific bearing model no. ESCALAB $\mathrm{Xi}+$ instrument. Thermal probe was carried out by thermogravimetric analysis (TGA) on model STA 409 Metzsch Geratebau GMBH (Germany) under nitrogen flow at a pressure of 1.5 bar and flow rate of $2 \mathrm{~L} / \mathrm{h}$. The catalyst (MAFPA) mass transfer and phase transition was studied in range between $10{ }^{\circ} \mathrm{C}-1000{ }^{\circ} \mathrm{C}$ with constant nitrogen gas flow. Scanning electron microscope coupled with EDS analysis (determination of elemental composition) of the catalyst was carried out on model no JEOL JSM-7600F. SEM images were captured on a FEI Quanta 200 F, using X-ray source made up of tungsten filament doped with Lanthanum hexaboride $\left(\mathrm{LaB}_{6}\right)$ and connected with an ETD as secondary electrons detector operated at high vacuum with an acceleration tension of $30 \mathrm{kV}$. Samples are analyzed by spreading them on a carbon tape. JEM2100 equipment was used to capture transmission electron microscopy images of the catalyst. Surface area and pore volume of the MPS was found out by BrunauerEmmett-Teller (BET) study and the analysis result as $\mathrm{N}_{2}$ adsorption-desorption isotherm was determined on Micromeritics ASAP 2010 using He as carrier gas. Prior to analysis the catalyst was made moisture and atmospheric vapour free by degassing at $180{ }^{\circ} \mathrm{C}$ for $12 \mathrm{~h}$. Furthermore the basic strength was tested by Hammett indicator method using the following indicators with different acidity functions $\left(\mathrm{H}_{-}\right)$; phenolphthaleine $\left(\mathrm{H}_{-}=9.8\right)$, indigo carmine $\left(H_{-}=12.2\right), 2$, 4-dinitroaniline $\left(H_{-}=15.0\right)$ and 4-nitroaniline $\left(H_{-}=18.4\right)$. An anhydrous ethanol was used in the reaction. In the experimental run, $50 \mathrm{mg}$ of catalyst and $10 \mathrm{~mL}$ of anhydrous ethanol were taken in a $25 \mathrm{~mL}$ round bottom flask and shaken well. The reactants were then allowed to rest for $2 \mathrm{~h}$ to attain a state of equilibrium. The gradual change in 
reaction colour indicates the base strength of the catalyst. When the catalyst strength is higher than the weakest indicator, a change in solution colour is observed while it remains unchanged when the catalyst strength is lower than the strongest indicator.

\subsection{Pretreatment of waste cooking oil}

Waste cooking oil was obtained from a hotel in Silchar, Assam, India. A filtered paper was used to make the oil free of crude impurities. The filtrate was then washed 3 times with hot water to eliminate the impurities and the mixture was allowed to settle, which was then separated using the separating funnel. The washed oil was then heated at $120^{\circ} \mathrm{C}$ for $2 \mathrm{~h}$ to remove moisture from the oil. The oil obtained was treated with charcoal to remove any remaining colored impurities. The saponification value and acid value of the pretreated WCO were found to be $184.37 \mathrm{mg} \mathrm{KOH} \mathrm{g}^{-1}$ and $1.95 \mathrm{mg} \mathrm{KOH} \mathrm{g}^{-1}$. The oil was further used for the transesterification reaction with methanol in the presence of MAFPA catalyst.

\subsection{Transesterification of WCO}

As free fatty acid (FFA) was found to be $<2 \%$, it required only one step transesterification for the conversion of WCO to WCME (Mansir et al., 2018; Tan et al., 2015). In this study, transesterification process was performed at room temperature $\left(28^{\circ} \mathrm{C}\right)$ in a round bottom (RB) flask placed on a magnetic stirrer. The desired amount of methanol, oil and MAFPA was taken in a $\mathrm{RB}$ and the reaction was carried out for a specific time span. All the experimental runs were performed sequentially according to the transesterification parameters (MAFPA concentration, M/O ratio and time) value provided by CCD of RSM. The parameters selected for designing the experimental run with CCD are shown in Table 1. Once the reaction time was completed the resultant mixture was subjected to heating for a particular time period in order to remove the excess methanol followed by separation of catalyst from the reaction mixture through centrifuged at $3000 \mathrm{rpm}$. Next, the two layers were obtained which consists of the WCME (biodiesel) at the top layer and the prepared catalyst with glycerol at the bottom layer. The top layer containing WCME is collected and stored in an airtight container for further analysis. The oil conversion after each run is estimated using ${ }^{1} \mathrm{H}$ NMR which is carried out on Bruker Avance II (400 MHz) spectrometer using $\mathrm{CDCl}_{3}$ as solvent and tetramethylsilane (TMS) as an internal reference. The percentage conversion of WCO to WCME was estimated using Eq. 1 given by Knothe (Knothe and Kenar, 2004).

$$
\% W C M E=100 X \frac{2 A_{M e}}{3 A_{C H_{2}}}
$$


Where, \%WCME is the percentage conversion of triglycerides to methyl esters. The factors 2 and 3 were derived from the number of attached protons at the $\alpha$-carbonyl methylene and methoxy carbons, respectively. $A_{M e}=$ integration value of methoxy groups of methyl esters $A_{\mathrm{CH}_{2}}=$ integration value of $\alpha$ - carbonyl methylene groups in fatty ester derivatives. The conversion percentage (FAME conversion) was estimated by taking the integrated areas obtained from the peaks of methoxy groups $\left(\mathrm{A}_{\mathrm{Me}}\right)$ in the FAME and $\alpha-\mathrm{CH}_{2}$ protons present in the triglycerides of waste cooking oil. The constituent of final biodiesel obtained with optimized conditions was determined by Agilent 7890-GC, Jeol AccuTOF GCV-MS.

\subsection{Experimental design for maximum biodiesel yield}

Here in this study central composite design (CCD) coupled with surface methodology (RSM) has been used for designing and modelling the experiments as well as optimizing WCME. The application of CCD in the optimization of biodiesel using MAFPA catalyst as well as the effect of key variables (M/O molar ratio, catalyst concentration and reaction time) on the yield has been discussed here. Twenty different experimental runs were conducted separately $\left(2^{p}+2 p+c\right.$, where, $p=$ number of factor and $c=$ center points number $)$. The $2^{p}$ design in the current case with center points needed fewer runs whereby giving identical details regarding curvature as shown by a $3^{\mathrm{p}}$ design (Tan et al., 2019). The current CCD model comprises of $2^{3}$ $=8$ factorial points, $2 \times 3=6$ axial and $b=6$ center points. The axial point $\alpha$ in this study is selected to be 1.68. The independent variables along with their upper and lower limits can be seen from Table 1. Finally the CCD matrix in Table 2 shows the whole design matrix including real and coded independent variables.

To correlate the biodiesel conversion as response to the transesterification process variables, a mathematical model is developed. The interaction of input variables with output (biodiesel conversion) is formulated in following equation (Eq. 2).

$$
Y=\beta_{O}+\sum_{i=1}^{n} \beta_{i} X_{i}+\sum_{i=1}^{n} \beta_{i i} X_{i}^{2}+\sum_{i=1}^{n} \sum_{j=1}^{i-1} \beta_{i j} X_{i} X_{j}+\varepsilon_{i}
$$

Where, $Y=$ response, (WCME conversion), $X_{i} X_{j}=$ Independent variable, $\beta_{O}$, =intercept $\beta_{i}=$ first model co-efficient, $\beta_{i i}=\mathrm{i}$ factor quadratic co-efficient, $\beta_{i j=}$ linear coefficients of the model for the interaction between $\mathrm{i}$ and $\mathrm{j}$ factors, $\varepsilon=$ The experimental error ascribed to $\mathrm{Y}$.

Analysis of variance (ANOVA) was examined in Design-Expert 11.0 software. Next P-test and F-test were done on each coefficient to ensure the statistical significance of each term in 
the fitted equation. The considerable value for $\mathrm{F}$ (within the level of $95 \%$ ) and $\mathrm{p}(<0.05)$ was chosen for model to be significant (Yatish et al., 2016) $\mathrm{n}$ top of this, the operational parameters were tested with regression and graphical analysis to quantify its optimal values.

The regression coefficient of determination or relative standard error (RSE) between the experimental and predicted outcomes was to determine the model reliability (Nayak and Vyas, 2019). The RSE is estimated by Eq. (3). The average RSE lower than $10 \%$ was acceptable (Barekati-Goudarzi et al., 2016).

$$
R S E \%=\sum_{i=1}^{n} \frac{\left|Y_{\text {exp }}-Y_{\text {pre }}\right|}{Y_{\text {exp }}} * \frac{100}{n}
$$

Where, Yexp= experimental value, Ypre $=$ value obtained from model, $\mathrm{n}=$ total number of results

Table1: Variables and experimental conditions of transesterification for 3 factor five level CCD design of RSM

\begin{tabular}{|c|c|c|c|c|c|c|c|c|c|c|c|}
\hline \multirow{2}{*}{\multicolumn{2}{|c|}{ Variables }} & & \multirow{2}{*}{\multicolumn{2}{|c|}{ Symbol }} & \multirow[b]{2}{*}{ units } & \multicolumn{5}{|c|}{ Level } & \\
\hline & & & & & & $-\alpha$ & -1 & 0 & 1 & $+\alpha$ & \\
\hline \multicolumn{3}{|c|}{ MAFPA } & \multicolumn{2}{|l|}{$\mathrm{A}$} & $\% \mathrm{w} / \mathrm{w}$ & 1.98 & 3 & 4.5 & 6 & 7.02 & \\
\hline \multicolumn{12}{|c|}{ Concentration } \\
\hline \multicolumn{3}{|c|}{$\mathrm{M} / \mathrm{O}$ ratio } & B & \multicolumn{2}{|c|}{$\mathrm{mol} / \mathrm{mol}$} & \multicolumn{2}{|c|}{3.98} & 6.5 & 8 & 9.02 & \\
\hline \multicolumn{3}{|c|}{ Time } & $\mathrm{C}$ & \multicolumn{2}{|r|}{$\mathrm{h}$} & \multicolumn{2}{|c|}{1.32} & 3 & 4 & 4.68 & \\
\hline \multicolumn{11}{|c|}{$\begin{array}{l}{ }^{*} \alpha=1.68179, \text { variable converted from coded }(C) \text { to } \\
\text { are as follows } A=10 X+40, B=1.5 X+6.5, C=X+3\end{array}$} & \\
\hline \multirow{5}{*}{\multicolumn{2}{|c|}{$\begin{array}{c}\text { Runt } \\
\text { type }\end{array}$}} & \multirow{2}{*}{\multicolumn{2}{|c|}{$\begin{array}{c}\text { MAFPA } \\
\text { Concentrati } \\
\end{array}$}} & \multirow{3}{*}{\multicolumn{2}{|c|}{$\begin{array}{l}\mathrm{M} / \mathrm{O} \text { molar } \\
\text { ratio } \\
(\mathrm{mol} / \mathrm{mol})\end{array}$}} & \multirow{3}{*}{\multicolumn{2}{|c|}{ Time (h) }} & \multirow{3}{*}{\multicolumn{3}{|c|}{$\begin{array}{c}\text { Biodiesel Conversion } \\
(\%)\end{array}$}} & \multirow{5}{*}{$\begin{array}{c}\mathrm{RSE} \\
\%\end{array}$} \\
\hline & & & & & & & & & & & \\
\hline & & \multicolumn{2}{|c|}{ on } & & & & & & & & \\
\hline & & $\mathrm{UC}$ & $\mathrm{C}$ & $\mathrm{UC}$ & $\mathrm{C}$ & \multirow{2}{*}{$\mathrm{UC}$} & \multirow[t]{2}{*}{$\overline{\mathrm{C}}$} & \multirow{2}{*}{\multicolumn{3}{|c|}{$\overline{\text { Experimenta predicted }}$}} & \\
\hline & & & & & & & & & & & \\
\hline 1 & Fact & 3 & -1 & 5 & -1 & 4 & 1 & 5 & & 54.75 & 1.39 \\
\hline 2 & Centre & 4.5 & 0 & 6.5 & 0 & 3 & 0 & 85. & & 86.27 & 0.62 \\
\hline 3 & Fact & 6 & 1 & 5 & -1 & 2 & -1 & 46. & & 47.94 & 2.26 \\
\hline 4 & Fact & 6 & 1 & 8 & 1 & 2 & -1 & 3 & & 33.85 & 0.44 \\
\hline 5 & Axial & 7.02 & $+\alpha$ & 6.5 & 0 & 3 & 0 & 77. & & 77.34 & 0.3 \\
\hline
\end{tabular}




\begin{tabular}{rcccccccccc}
6 & Fact & 3 & -1 & 8 & 1 & 4 & 1 & 60.29 & 59.83 & 0.76 \\
7 & Axial & 4.5 & 0 & 6.5 & 0 & 1.3 & $-\alpha$ & 19 & 18.02 & \\
& & & & & & 2 & & & & 5.16 \\
8 & Axial & 4.5 & 0 & 6.5 & 0 & 3 & 0 & 85.78 & 86.27 & 0.57 \\
9 & Fact & 6 & 1 & 5 & -1 & 4 & 1 & 95.28 & 94.53 & 0.79 \\
10 & Fact & 4.5 & 0 & 6.5 & 0 & 3 & 0 & 86.82 & 86.27 & 0.63 \\
11 & Fact & 4.5 & 0 & 6.5 & 0 & 4.6 & $+\alpha$ & 83.84 & 83.94 & \\
& & & & & & 8 & & & & 0.12 \\
12 & Axial & 4.5 & 0 & 9.02 & $+\alpha$ & 3 & 0 & 57.56 & 56.99 & 1 \\
13 & Centre & 4.5 & 0 & 6.5 & 0 & 3 & 0 & 86.63 & 86.27 & 0.42 \\
14 & Fact & 3 & -1 & 5 & -1 & 2 & -1 & 31.29 & 31.18 & 0.35 \\
15 & Axial & 4.5 & 0 & 3.98 & $-\alpha$ & 3 & 0 & 64.84 & 64.57 & 0.42 \\
16 & Centre & 4.5 & 0 & 6.5 & 0 & 3 & 0 & 87.53 & 86.27 & 1.44 \\
17 & Axial & 1.98 & $-\alpha$ & 6.5 & 0 & 3 & 0 & 39.58 & 38.96 & 1.57 \\
18 & Fact & 4.5 & 0 & 6.5 & 0 & 3 & 0 & 85 & 86.27 & 1.5 \\
19 & Fact & 3 & -1 & 8 & 1 & 2 & -1 & 26.64 & 27.99 & 5.06 \\
20 & Centre & 6 & 1 & 8 & 1 & 4 & 1 & 88 & 88.71 & 0.8 \\
& & & & & & & & & & Avg RSE \\
\hline & & & & & & $1.28 \%$ & & & & \\
\hline
\end{tabular}

\subsection{Maximizing the yield using Particle swarm optimization (PSO)}

Inspired by the social, especially the foraging nature of the birds in nature, a metaheuristic algorithm has been developed by Kennedy and Eberhart (Kennedy and Eberhart, 1995) in the year 1995. PSO works by initiating a swarm of hypothetical birds or particles in a threedimensional space and assigning them certain velocities. In this 3D design space, the position of each particle is represented by time, catalyst concentration and M/O ratio. Every position represents a potential solution of the problem and these solutions are evaluated with respect to the objective function which is the yield in the present case. The beauty of this algorithm is its inherent ability to maintain a fine balance between intensification and diversification in order to explore the entire domain as well as exploit the promising regions in the later stages of the run. PSO functions by obeying the following update equations: 
To initiate the search process, a swarm of hypothetical particles (that represent potential solutions of the problem) are generated and assigning random velocities to the particles. The objective function values are evaluated with respect to the positions of the agents and their individual fitness values (p-best) and the fitness value of the best particle ( $\mathrm{g}$ best) is recorded (Kennedy and Eberhart, 1995). Here it is worth mentioning that the initial positions of all the particles are their respective personal bests. Based on these two values the particles update or change their positions and velocities by obeying the following equations:

$$
\begin{aligned}
& v^{d}{ }_{i+1}=v_{i}^{d}+c_{1} r_{1}\left(\text { pbest }_{i}^{d}-x_{i}^{d}\right)+c_{2} r_{2}\left(\text { gbest }_{i}-x_{i}^{d}\right) \\
& x^{d}{ }_{i+1}=x^{d}{ }_{i}+v^{d}{ }_{i+1}
\end{aligned}
$$

The velocity equation has three principal segments which equally contribute to the particles' movement through the problem space. The first term takes in to account the influence of the particles' previous velocity on the new velocity. A linearly decreasing inertia factor ' $w$ ' has been linked with this term which efficiently maintains the balance between intensification and diversification. The second and third terms are cognitive and social components which scales the distance between particle's best position as well as the group's best position and the current position.

What makes PSO superior to the particles retain the memory of the locations in the domain. The algorithm runs in an iterative fashion by constantly improving the positions of the particles and finally converging at a near optimal point. After every iteration, the positions are updated and the particles are made to move toward the best particle of the swarm. Soon within a few iterations, the particles converge near a good optimum value in the vicinity of the global best position. Here a linearly decreasing inertia weight is employed which makes the algorithm scan the multi-dimensional domain in the initial iterations and gradually converge to a promising optimum value at the end of the run (Deshamukhya et al., 2020). To ensure efficient functioning of the algorithm, the algorithm centric parameters should be judicially selected. It is quite logical to believe that more the number of agents better will be the result. However increasing the number of agents increases the computational effort without much improvement in the output. So the number of particles in the swarm should neither be too less nor too large.

\section{Results and Discussion}




\section{1 catalyst characterization}

To identify the specific composition of the banana flower petals ash (MAFPA) catalyst, XRF analysis was conducted and the results are presented in Table 3.

\begin{tabular}{|c|c|c|}
\hline SI No. & $\begin{array}{l}\text { Compound } \\
\text { formula }\end{array}$ & Weight (\%) \\
\hline 1 & $\mathrm{~K}_{2} \mathrm{O}$ & 60.23 \\
\hline 2 & $\mathrm{SiO}_{2}$ & 21.3 \\
\hline 3 & $\mathrm{MgO}$ & 4.78 \\
\hline 4 & $\mathrm{Cl}$ & 3.91 \\
\hline 5 & $\mathrm{P}_{2} \mathrm{O}_{5}$ & 3.65 \\
\hline 6 & $\mathrm{CaO}$ & 3.17 \\
\hline 7 & $\mathrm{Na}_{2} \mathrm{O}$ & 1.11 \\
\hline 8 & $\mathrm{SO}_{3}$ & 0.71 \\
\hline 9 & $\mathrm{Fe}_{2} \mathrm{O}_{3}$ & 0.19 \\
\hline 10 & $\mathrm{TiO}_{2}$ & 0.18 \\
\hline 11 & $\mathrm{ZnO}$ & 0.16 \\
\hline 12 & $\mathrm{Al}_{2} \mathrm{O}_{3}$ & 0.15 \\
\hline 13 & $\mathrm{Rb}_{2} \mathrm{O}$ & 0.13 \\
\hline 14 & $\mathrm{SrO}$ & 0.12 \\
\hline 15 & $\mathrm{CuO}$ & 0.1 \\
\hline 16 & $\mathrm{MnO}$ & 0.07 \\
\hline 17 & $\mathrm{Cr}_{2} \mathrm{O}_{3}$ & 0.04 \\
\hline
\end{tabular}

The important components which are responsible for catalytic activity in MAFPA catalyst as found from the analysis are potassium oxide $(60.23 \%)$ silicon dioxide $(21.3 \%)$, magnesium oxide $(4.78 \%)$ calcium oxide $(3.17 \%)$, chloride $(3.91 \%)$ and phosphorus pentoxide $(3.65 \%)$. Some metal oxides in minimal amount are also traced from the analysis which are listed in Table 3. A close inspection of Table 3 reveals that a highly basic $\mathrm{K}_{2} \mathrm{O}$ is the major component of the proposed mango peel ash that boost its catalytic activity to a great extent. It is a well known fact that the mixed metal oxide performs better in transesterification reaction as compared to single metal oxide as catalyst (Laskar et al., 2019; 
Madhuvilakku and Piraman, 2013; Rabie et al., 2019). This translates to the fact that since the current MAFPA catalyst is composed of mixed metal oxides, an enhanced catalytic performance in the reaction can be expected. Rabie et al. improved the transesterification reaction using dolomite supported $\mathrm{CaO}$ and $\mathrm{MgO}$ (dolomite@ $\mathrm{CaO} / \mathrm{MgO}$ ) catalyst (Rabie et al., 2019). Hence, the presence of $\mathrm{CaO}$ and $\mathrm{MgO}$ in MAFPA further increases the efficiency of the present catalyst in the reaction.

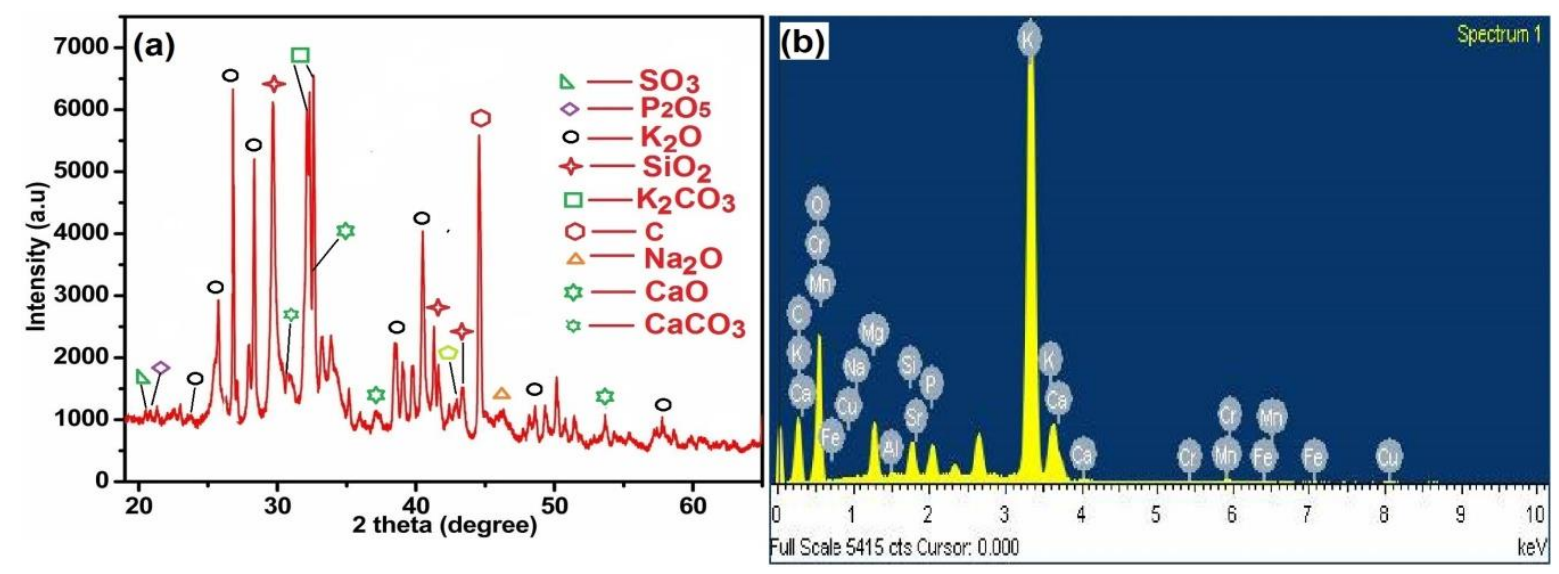

Fig. 1: a) XRD pattern of MAFPA b) EDS spectra of MAFPA

The results of XRD analysis of MAFPA is shown in Fig. 1a. It is evident from the figures that the major components of MAFPA are metal oxides and carbonates where potassium oxide and potassium carbonate are found to be present in high abundance. These can be seen from the characteristic peaks at 2 theta values which include 23.56, 25.37, 26.81, 28.56, 32.17, 32.7, 38.49, 40.50, 48.5 and 57.91 (JCPDS reference file no: 26-1327 and 491093). $\mathrm{CaCO}_{3}$ and $\mathrm{CaO}$ were detected at $2 \theta=30.3,32.31,37.21,53.65$ (JCPDS file no 871863 and 48-1467). The $\mathrm{SiO}_{2}$ present in MAFPA can be determined from the inhabitancy of peaks at $2 \theta=29.72,41.31$ and 43.45 (JCPDS file no 81-0069). Apart from the above mentioned constituents, various other peaks obtained at 2 theta values of 20.21, 20.86, 42.95, 46.31 and 44.65 are due to $\mathrm{SO}_{3}, \mathrm{P}_{2} \mathrm{O}_{5}, \mathrm{MgO}, \mathrm{Na}_{2} \mathrm{O}$ and $\mathrm{C}$ molecules respectively assured from JCPDS file no 72-1664, 87-0952, 87-0652, 77-2148 and 80-0017. 34. We have earlier reported similar XRD pattern for Musa acuminata peel ash (Pathak et al., 2018).

EDS analysis was done to get an idea about various elements present in the MAFPA and results are presented in Fig. 1b. The analysis revealed the presence of K (45.44\%), O (41.84\%), Ca (2.4\%), P (2.03\%), Mg (3.05\%), Si (1.95\%), C (1.9\%), Mn (0.67\%), Fe $(0.25 \%), \mathrm{Sr}(0.37 \%)$, and $\mathrm{Al}(0.09 \%)$. The results obtained from EDS analysis is in good agreement with XRF and XRD analyses. In a study by Madhuvilakku et al. the authors found 
that the catalytic $\left(\mathrm{ZnO}-\mathrm{TiO}_{2}\right)$ activity of mixed metal oxide in transesterification is significantly higher than their single oxide counterparts (Madhuvilakku and Piraman, 2013). Hence, it is anticipated that the presented catalyst would exhibit better performance in the reaction due to the presence of several metal oxides in it inherently.

Further, a thermogravimetric analysis (TGA) was performed for MAFPA catalyst and the results are furnished in Fig. 2a. A steady fall of $1.89 \%$ in weight up to $110{ }^{\circ} \mathrm{C}$ (due to evaporation) can be read from the trend seen in the figure (Mendonça et al., 2019). Again under the influence of $\mathrm{N}_{2}$, the weight of MAFPA further drops by $9.83 \%$ in between $115^{\circ} \mathrm{C}$ $290{ }^{\circ} \mathrm{C}$ due to thermal decomposition of catalyst (Pathak et al., 2018), while after $290{ }^{\circ} \mathrm{C}$, the further drop in weight is due to carbonaceous material of MAFPA undergoing oxidation and elimination of $\mathrm{CO}_{2}$, CO etc (Chouhan and Sarma, 2013; Mendonça et al., 2019; Pathak et al., 2018) .
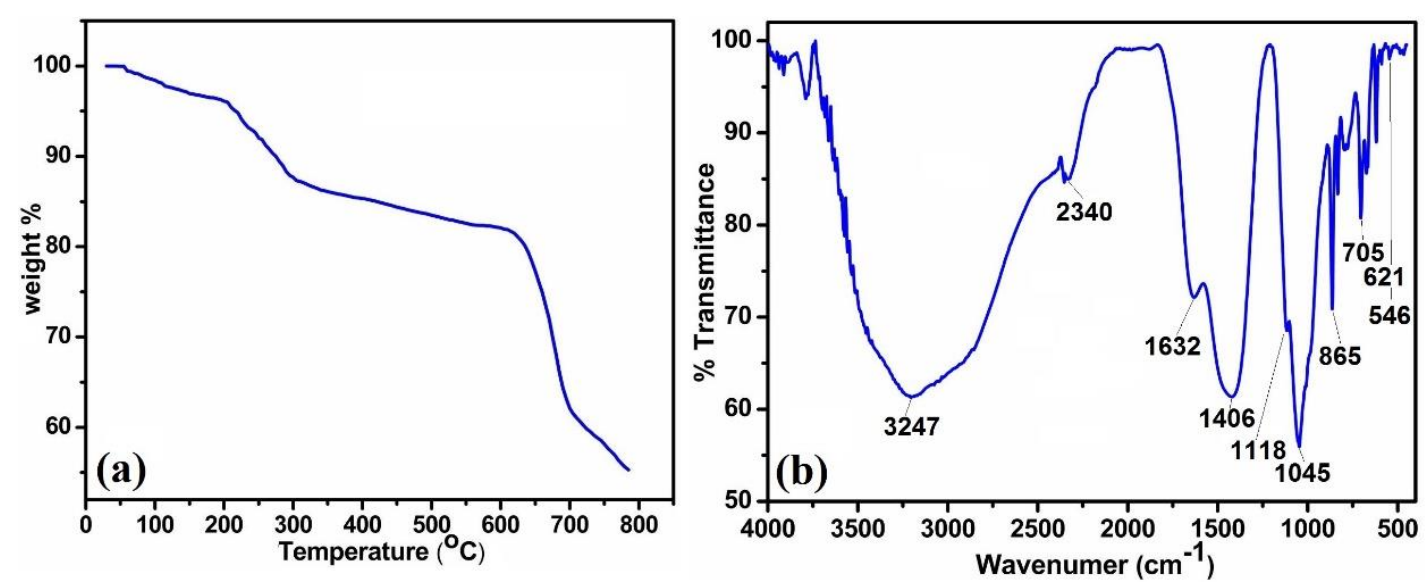

Fig. 2 : a) TGA pattern of MAFPA, b) FTIR spectra of MAFPA

To get information about the functional group attached to the MAFPA, FTIR analysis was performed. Fig. $2 b$ depicted the presence of number of bands appear at different wave numbers. The band appearing at $3210 \mathrm{~cm}^{-1}$ corresponds to $\mathrm{O}-\mathrm{H}$ stretching and at can be attributed to $\mathrm{H}_{2} \mathrm{O}$ bending vibration (Betiku et al., 2016; Pathak et al., 2018; Sharma et al., 2012). The bands at $1640,1398,1122$ and $705 \mathrm{~cm}^{-1}$ are due to $\mathrm{C}-\mathrm{O}$ stretching and bending vibrations which are the characteristic peaks of metal carbonates $\left(\mathrm{CO}_{3}\right)$, while the peak at $1398 \mathrm{~cm}^{-1}$ is due to $\mathrm{K}_{2} \mathrm{CO}_{3}$ (Betiku et al., 2016; Laskar et al., 2018a). The metal oxide surfaces adsorb $\mathrm{CO}_{2}$ from the environment which results in the formation of metal carbonates in MAFPA (Pathak et al., 2018). However the bands at 1051 and $621 \mathrm{~cm}^{-1}$ and the band at $2340 \mathrm{~cm}^{-1}$ are due to the stretching of Si-O-Si (Betiku et al., 2016) and M-O-K bonds (M = 
$\mathrm{Si}, \mathrm{Mg}$, etc.) respectively. While the absorption bands at $864 \mathrm{~cm}^{-1}$ is due to isolated vibration of $\mathrm{SiO}_{4}$, in $\mathrm{CaMgSiO}_{4}$. This may be due to interaction of $\mathrm{Ca}^{2+}$ and $\mathrm{Mg}^{2+}$ with $\mathrm{SiO}_{4}(\mathrm{Betiku}$ et al., 2016).

Further, SEM and TEM images of MAFPA were captured with an aim to get a clear view of the catalyst's peripheral morphology. Number of aggregate surfaces with mesoporous structure can be seen in Fig. 3a-c. MAFPA exhibited porous glossy/ glassy and spongy particles (Fig. 3c and 3e). Similar morphological surface has been obtained from banana peel ash in our past studies (Pathak et al., 2018). A strong resemblance of results obtained by TEM analysis with that of SEM analysis has been noticed. From Fig. 3d, porous nature and assemblage of the particles can be seen from Fig. 3d. The crystalline nature of the particles was observed in the image obtained from SAED in Fig 3f.
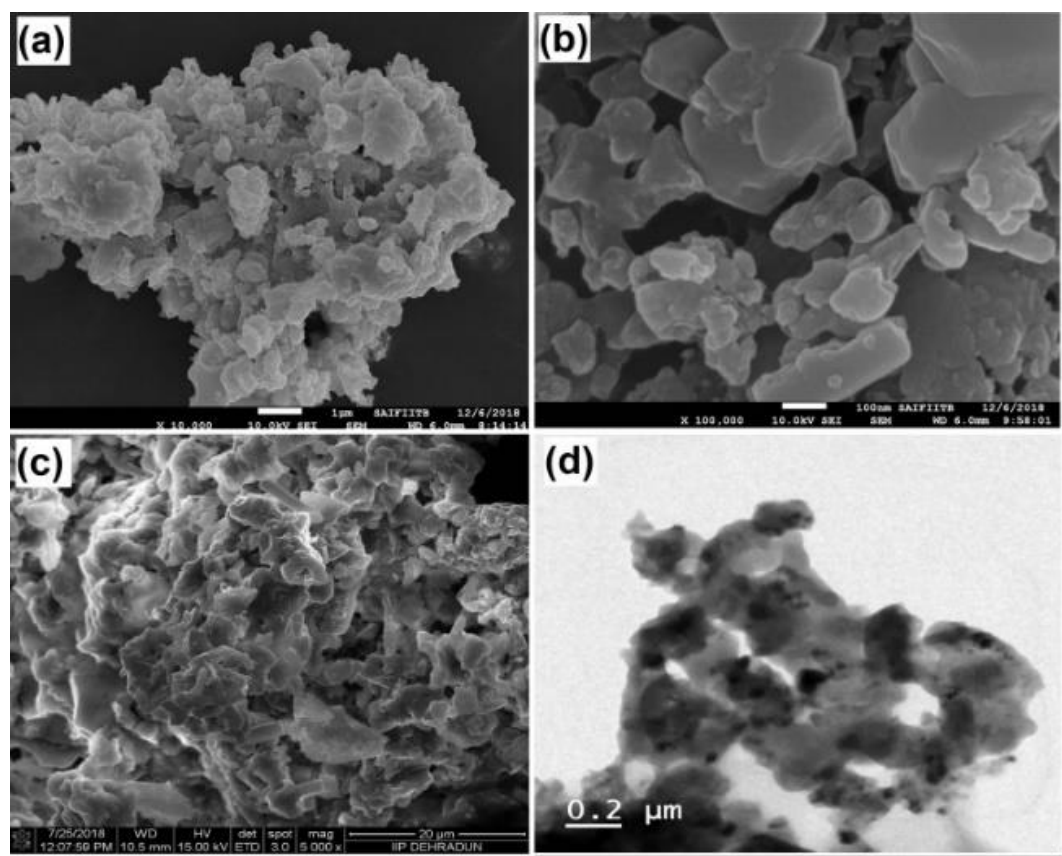

(d)
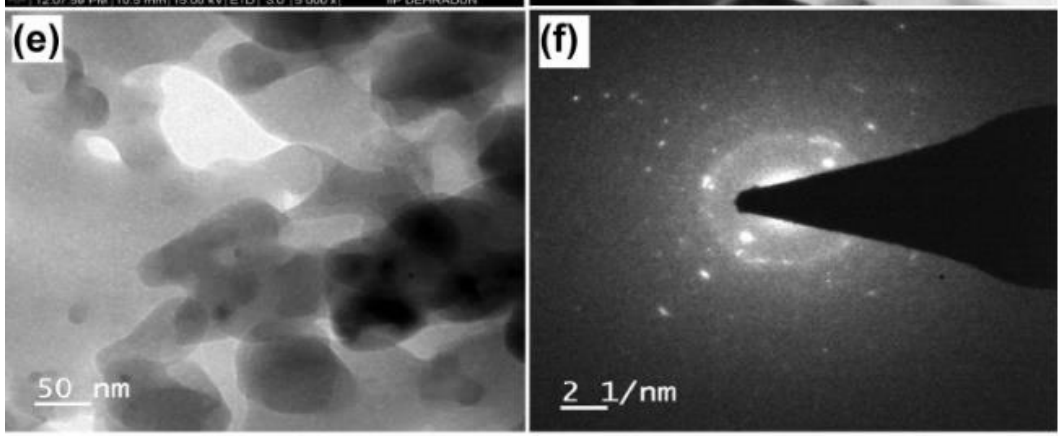

Fig. 3: SEM images (a-c), TEM images (d,e), SAED pattern (f) 
A type- IV hysteresis loop which is a characteristic of mesoporous materials is obtained in $\mathrm{N}_{2}$ adsorption - desorption isotherm of MAFPA (Fig. 4a). A clear insight about the pore size has been visualized from Fig. $4 \mathrm{~b}$ where it is seen that the pores obtained are in the range of 4-35 $\mathrm{nm}$. A similar mesoporous structure has been obtained in the SEM and TEM analysis. Surface area of $79.33 \mathrm{~m}^{2} \mathrm{~g}^{-1}$, pore volume of $0.260 \mathrm{~cm}^{3} \mathrm{~g}^{-1}$ and pore size of $9.71 \mathrm{~nm}$ were determined by BET method. The catalytic activity in transesterification reaction is greatly influenced by the surface area as well as the type of pore structure obtained (Lee and Wilson, 2015). The mesoporous structure helps in better diffusion of reactants inside the pores which eventually speeds up the reaction rate. This is in contrast to the microporous structures where reactions occur at the entrance; thereby reducing the rate of reaction (Da Silva et al., 2009; Laskar et al., 2018b; Lee and Wilson, 2015; Wang et al., 2019). The MAFPA being mesoporous in structure boosts biodiesel production to a large extent.

In order to have a concrete information about the constituents present on the catalyst's surface, XPS analysis was performed. The results (as displayed in Fig. 5) showed that the most prominent constituents present in the MAFPA surface are potassium (23.5\%), carbon (29.93\%), oxygen $(32.29 \mathrm{wt} \%)$, silicon $(2.89 \mathrm{wt} \%)$, calcium $(3.02 \mathrm{wt} \%)$, chlorine $(2.26 \mathrm{wt} \%)$, Along with these, magnesium $(1.77 \mathrm{wt} \%)$, phosphorus $(1.46 \% \mathrm{wt} \%)$, manganese $(0.7 \mathrm{wt} \%)$, iron $(0.15 \mathrm{wt} \%)$, strontium $(0.77 \mathrm{wt} \%)$, Aluminium $(0.61 \mathrm{wt} \%)$ and copper $(0.35 \mathrm{wt} \%)$ were also present in a limited amounts. It can be seen from Fig. $5 \mathrm{~b}$ that $\mathrm{C} 1 \mathrm{~s}$ signal is split into three parts along the binding energy through deconvolution. The peaks obtained can be attributed to the presence of adventitious carbon $(283.53 \mathrm{eV}), \mathrm{C}=\mathrm{O}(284.53 \mathrm{eV})$ and $\mathrm{CO}_{3}{ }^{2-}$ $(288.33 \mathrm{eV})$ (Correia et al., 2014). However, in the O 1s core level spectrum (Fig. 5c), the presence of three different peaks at 529.63, 530.81 and $532.54 \mathrm{eV}$ are due to the inhabitancy of metal oxide, alumina, and metal carbonates respectively in the MAFPA catalyst (Pathak et al., 2018).
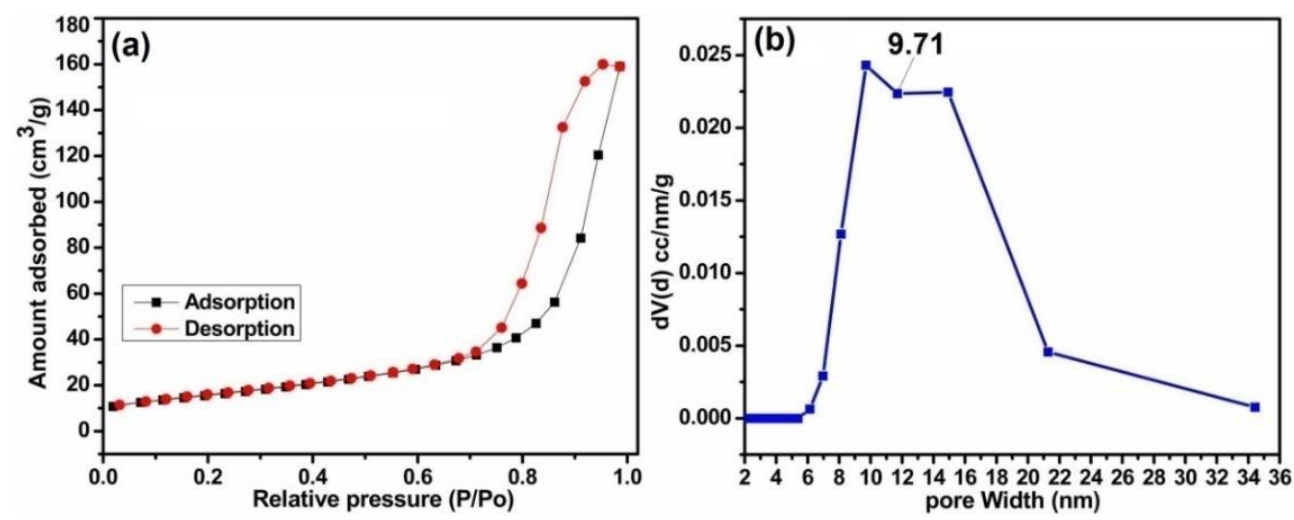

Fig. 4: BET result of MAFPA a) $\mathrm{N}_{2}$ adsorption-desorption isotherm b) pore size 


\section{distribution}

Two peaks seen at 291.7 and $294.4 \mathrm{eV}$ for $\mathrm{K} 2 \mathrm{p}$ indicated the presence of potassium bonded with carbonate and oxides (Fig 5d) (Changmai et al., 2019a). The peaks obtained at 345.66 and $350.18 \mathrm{eV}$ testify the presence of calcium carbonate and calcium oxide in the catalyst. [Supplementary Information (SI) Fig. S1a]. From Si 2p spectrum, (Fig. S1b), it can be stated that peak at $104.4 \mathrm{eV}$ is due to $\mathrm{SiO}_{2}$ whereas the peak obtained at $101.36 \mathrm{eV}$ can be attributed to silicate species.

Similarly, Mg 1s spectrum shows two peaks at 1303.54 and $1301.46 \mathrm{eV}$ respectively Fig. S1c). This can be credited to the bonding of $\mathrm{Mg}$ with $\mathrm{O}$ to form $\mathrm{MgO}$ and $\mathrm{CO}_{3}{ }^{2-}$ to form $\mathrm{MgCO}_{3}$ (Fig. S1c). Sulfur (S 2p) was found to be present in the catalyst in the form of sulfide and sulfate at 168.18 and $169.93 \mathrm{eV}$ respectively (Fig. S1d). The peaks at 131.73 and 133.99 $\mathrm{eV}$ in $\mathrm{P} 2 \mathrm{p}$ spectrum were due to the presence of phosphate species (Fig. S1e). Likewise, the peaks obtained at 197.7 and $199.7 \mathrm{eV}$ respectively on $\mathrm{Cl}$ 2p spectrum (Fig. S1f) hints toward the presence of chloride species in the catalyst.

Determining the basic strength of the catalyst is important as the reaction rate in base catalytic approach is highly influenced by its inherent basicity. The basic catalytic strength has been measured by Hammet indicator method which was found to be in between $15<\mathrm{H}_{-}$ $<$ 18.4. This finding estimated that the banana flower pallets ash catalyst is a strong base which can boost the transesterification at a faster rate. The high basic strength of the catalyst is mainly due to the presence of metal-O group. Birla et al. found similar basic strength value from snail shell catalyst (Birla et al., 2012). Pathak et al. observed the presence of various alkaline earth metals and alkali metals from Musa acuminata peel ash which is probably responsible for serving basic sites in transesterification reaction (Pathak et al., 2018). Here it is worth noting that the $\mathrm{K}$ in Musa acuminata peel ash is the major element. Thus $\mathrm{K}_{2} \mathrm{O}$ act as a strong base which is primarily responsible for high basic strength of the catalyst. Though the percentage of constituents varies marginally, yet a striking resemblance with respect to ingredients has been observed in between MAFPA and Musa acuminata peel ash. This similarity in characteristics can be a probable reason behind high basic strength of MAFPA. 

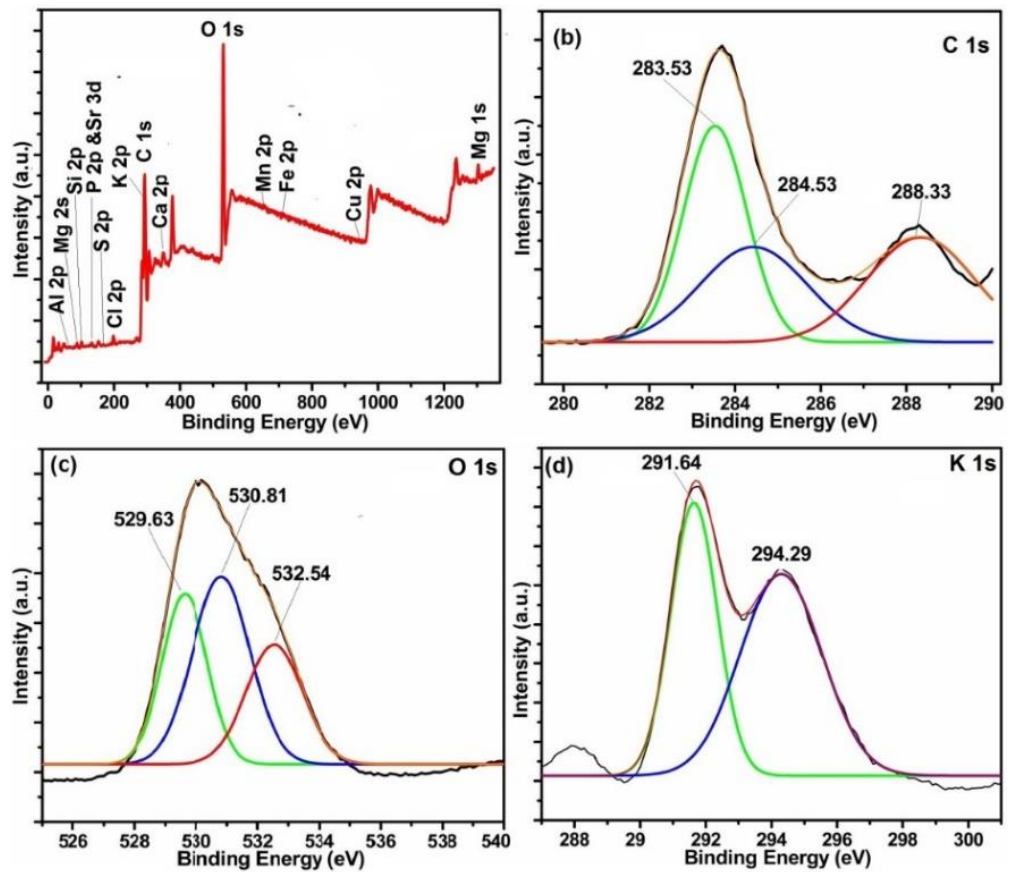

Fig. 5: XPS spectra of MAFPA a) Survey b) C 1s c) O 1s and d) K 1S core level spectra

\subsection{Optimisation of WCME conversion using RSM}

The experimental value of WCME conversion was examined by CCD to obtain a regression model. The fit summary (Table 4) has suggested quadratic model because of high values of $\mathrm{R}^{2}$. This has fixed the quadratic equation as best suited fit model for biodiesel conversion. A polynomial equation (Eq. 4) of second order was obtained through ANOVA analysis using design expert software to predict the WCME conversion.

Table 4: Fit summary of CCD model for WCME

\begin{tabular}{llllllll}
\hline Source & $\begin{array}{l}\text { Sequential } \\
\text { P value }\end{array}$ & $\begin{array}{l}\text { Lack } \\
\text { Fit }\end{array}$ & P & $\mathrm{R}^{2}$ & Adjusted & Predicted \\
& & & $\mathrm{R}^{2}$ & $\mathrm{R}^{2}$ & \\
& value & & & & \\
\hline Linear & 0.0017 & $<0.001$ & 0.6157 & 0.5437 & 0.4657 & \\
2FI & 0.6115 & $<0.0001$ & 0.6468 & 0.4838 & 0.0798 & \\
Quadratic & $<0.0001$ & 0.3405 & 0.9991 & 0.9982 & 0.9946 & Suggested \\
Cubic & 0.2131 & 0.6108 & 0.9995 & 0.9984 & 0.9654 & Aliased \\
\hline
\end{tabular}

WCME conversion $\%=86.27+11.41 * A-2.25 * B+19.61 * C-2.72 * A * B+$ $5.76 * A * C+2.07 * B * C-9.94 * A^{2}-9.01 * B^{2}-12.47 * C^{2}$ 
Where, transesterification parameters such as MAFPA concentration, M/O ratio and time are coded with $\mathrm{A}, \mathrm{B}$ and $\mathrm{C}$ respectively. The interaction between the parameters are defined as $\mathrm{AB}, \mathrm{BC}$ and $\mathrm{CA}$. Whereas, $\mathrm{A}^{2}, \mathrm{~B}^{2}$ and $\mathrm{C}^{2}$ are their square terms.

From the ANOVA analysis shown in Table 5 it can be seen that the probability (p) value of model is less than 0.0001 which signifies that the model is statically significant and can accurately predict the experimental values.

Table 5: ANOVA for WCME conversion

\begin{tabular}{|c|c|c|c|c|c|c|}
\hline Source & $\begin{array}{l}\text { Sum of } \\
\text { Squares }\end{array}$ & df & $\begin{array}{c}\text { Mean } \\
\text { Square }\end{array}$ & F-value & p-value & \\
\hline Model & $\begin{array}{r}11518.8 \\
1\end{array}$ & 9 & 1279.87 & 1188.10 & $<0.0001$ & Significant \\
\hline $\begin{array}{l}\text { A-MAFPA } \\
\text { concentration }\end{array}$ & 1778.11 & 1 & 1778.11 & 1650.61 & $<0.0001$ & \\
\hline $\begin{array}{l}\mathrm{B}-\text { Methanol/oil } \\
\text { ratio }\end{array}$ & 69.30 & 1 & 69.30 & 64.33 & $<0.0001$ & \\
\hline C-Time & 5251.64 & 1 & 5251.64 & 4875.07 & $<0.0001$ & \\
\hline $\mathrm{AB}$ & 59.40 & 1 & 59.40 & 55.15 & $<0.0001$ & \\
\hline $\mathrm{AC}$ & 264.96 & 1 & 264.96 & 245.96 & $<0.0001$ & \\
\hline $\mathrm{BC}$ & 34.20 & 1 & 34.20 & 31.74 & 0.0002 & \\
\hline $\mathrm{A}^{2}$ & 1424.53 & 1 & 1424.53 & 1322.39 & $<0.0001$ & \\
\hline $\mathrm{B}^{2}$ & 1170.99 & 1 & 1170.99 & 1087.03 & $<0.0001$ & \\
\hline $\mathrm{C}^{2}$ & 2241.66 & 1 & 2241.66 & 2080.92 & $<0.0001$ & \\
\hline Residual & 10.77 & 10 & 1.08 & & & \\
\hline Lack of Fit & 6.62 & 5 & 1.32 & 1.60 & 0.3104 & $\begin{array}{l}\text { not } \\
\text { significant }\end{array}$ \\
\hline Pure Error & 4.15 & 5 & 0.8302 & & & \\
\hline Cor Total & 11529.9 & 19 & & & & \\
\hline
\end{tabular}

The $\mathrm{R}^{2}$ value of 0.9991 too is a good indication of the model's ability to predict the experimental values with high accuracy. The significance of each factor was evaluated through P-value and Fisher's (F-Test). The experimental data are significant with confidence level of $95 \%$ because the model's $\mathrm{F}$ and $\mathrm{p}$ values are 1188 and $<0.0001$ respectively. The 
adjusted $\mathrm{R}^{2}$ of 0.9982 implies that the variability between predicted and actual values is $99.82 \%$. The $\mathrm{R}^{2}$ value 0.9991 signifies negligible deviation of predicted values from the actual ones. The lack of fit p-value as obtained from lack of fit test is 0.31 which shows the lack of fit to be insignificant. This testifies the fact that the experimental data has fitted successfully by considering interaction and contribution of all the factors in making regression response (Jaliliannosrati et al., 2013; Nayak and Vyas, 2019).
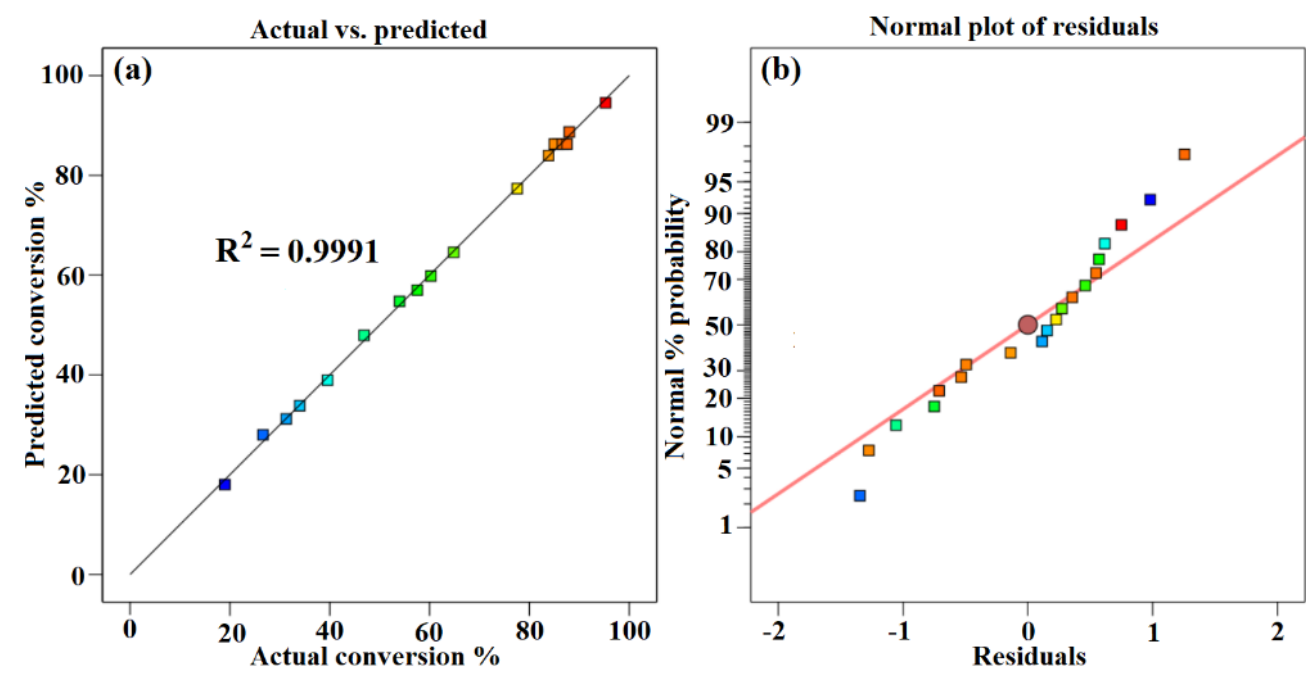

Fig. 6: Actual vs predicted conversion (a), normal plot of residual (b)

Fig. 6a represented the actual versus predicted WCME conversion and it is clearly seen that the predicted values were very close to the actual values. The normal probability plot of residual was illustrated in Fig. 6b. It was seen that the errors were distributed normally around the straight line. Any value outside the interval \pm 5 is interpreted as a probable cause of operational error in the experimental data (Ang et al., 2015). However in the present case the standard residual values fall in between \pm 2 has been obtained as seen in Fig. 7 . 


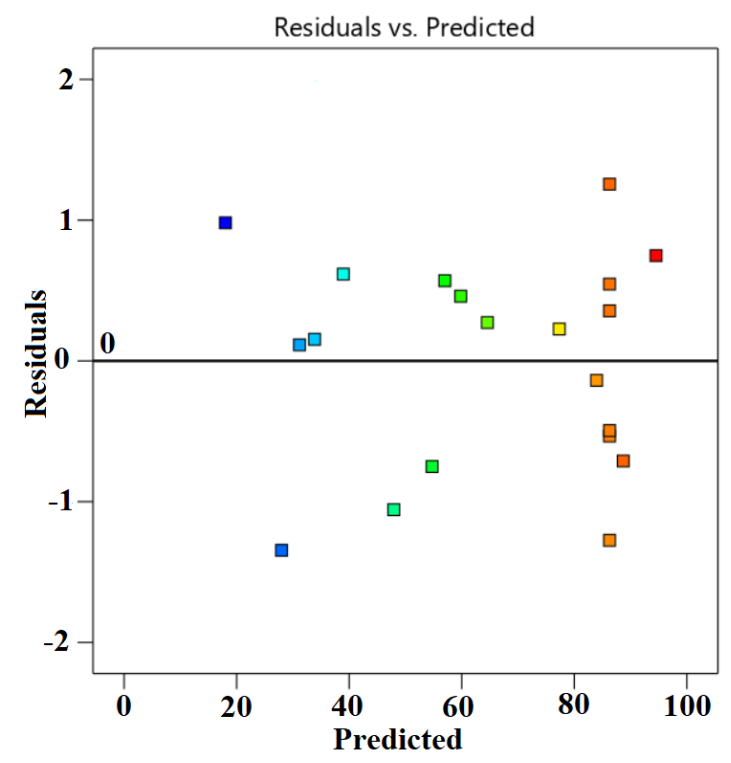

Fig. 7: Residual vs predicted

\subsection{Reaction parameters interactive effects on WCME conversion}

The effect of the interaction of MAFPA concentration (A) and M/O molar ratio (B) on WCME conversion is presented on Fig. 8. MAFPA concentration range was varied in between 1.98-7.02 wt.\% and M/O molar ratio was varied in between 3.98:1-9.02:1 whereas the third parameter time was fixed to $3 \mathrm{~h}$ at middle level. WCME conversion increased with the increase of parameter A and parameter B at minimum level (3.98). However, after 6.63 wt.\% the WCME conversion started falling with the rise in parameter A. The reason behind this can be attributed to the unavailability of methanol to shift the reaction forward. Hence, surplus methanol is required to take forward the reaction towards completion. Similar observation has also been reported by Mendonça et al. (Mendonça et al., 2019). On the other hand, the WCME conversion is affected by increasing the parameter B while keeping A fixed at $1.98 \mathrm{wt} \%$. When the parameter $\mathrm{B}$ increased beyond $6.86: 1 \mathrm{M} / \mathrm{O}$ molar ratio, the conversion of WCME conversion started dwindling. This trend of increase in conversion rate up to a certain limit is seen for all ranges of catalyst loading. A probable reason behind this is due to inhibition of the active catalyst surface by additional methanol. This results in lesser interaction or reaction of catalyst with WCO (Olutoye et al., 2011). The downfall in conversion can also be ascribed to the occurrence of reversible reaction. WCME reduction after a certain value has also been reported with Musa acuminate peduncle as a catalyst (Balajii and Niju, 2019). It can be noticed from the 3-D surface plot that the maximum conversion of WCME was attained in a range of 5.58- $6.3 \mathrm{wt} . \%$ and in a range of 6:14-6.86:1. 
The significant interaction among MAFPA concentration (A) and M/O molar ratio (B) is indicated by the lower $\mathrm{P}$ - value $(<0.0001)$ of $\mathrm{AB}$ from Table 5 .

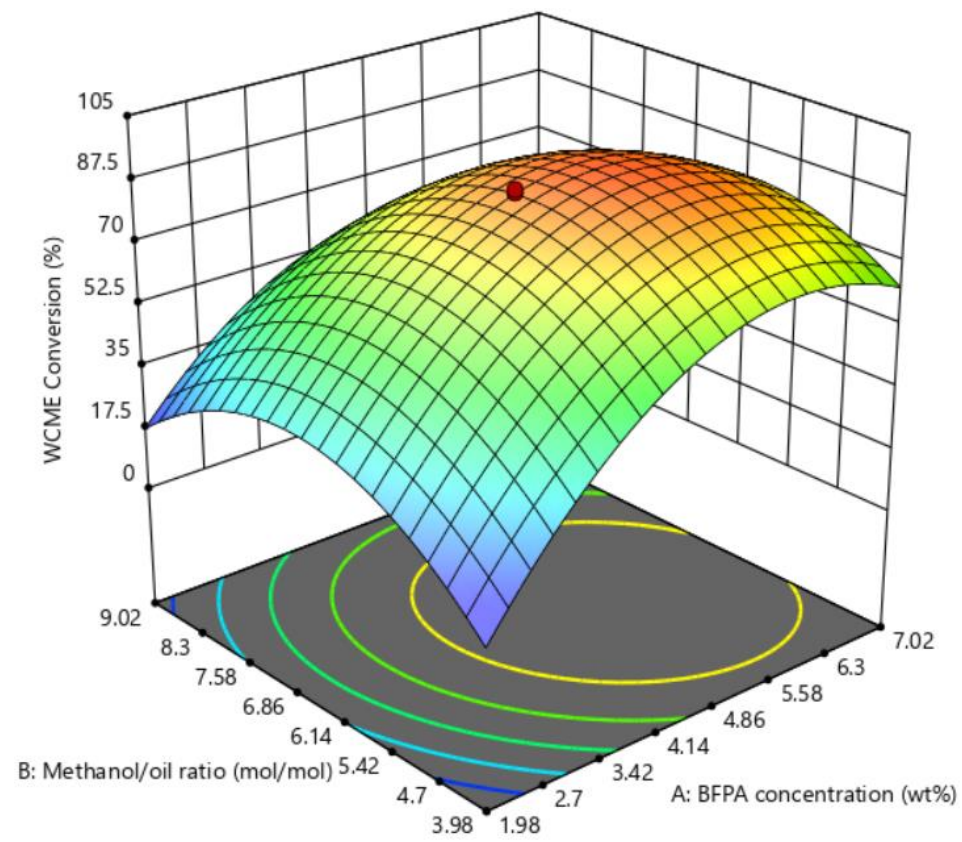

Fig. 8: Interaction effects of MAFPA concentration and

$\mathrm{M} / \mathrm{O}$ ratio

The interaction of MAFPA concentration (A) and the reaction time (C) in the transesterification influenced WCME conversion which is shown in Fig. 9. The interaction of $\mathrm{A}$ and $\mathrm{C}$ has been elucidated by keeping the parameter $\mathrm{B}$ constant at 6:5 $\mathrm{M} / \mathrm{O}$ ratio. The WCME conversion of $<35 \%$ was seen from the graph for the parameters A and C at low level which is ascribed to less active surfaces presence in the reaction and inadequate time for the complete transformation of WCO into WCME (Gohain et al., 2017). WCME conversion was increased sharply when the parameter A increased alone within a specific limit. This occured because of reactant's access to the high surface area $\left(79.33 \mathrm{~m}^{2} \mathrm{~g}^{-1}\right)$ of MAFPA catalyst resulting in high active sites to react and to move the reaction forward. A similar trend has also been obtained by other researchers in the past. Balajii et al. reported that the abrupt rise in biodiesel conversion with the rise in catalyst loading is due to high surface area of Musa acuminate peduncle ash catalyst while converting Ceiba pentandra oil to biodiesel (Balajii and Niju, 2019). Mendonça et al. noticed that the biodiesel conversion raised from $62.5 \%$ to $95.7 \%$ when catalyst loading is increased from 1 to 5 wt \% (Mendonça et al., 2019). But WCME conversion started to decline when the MAFPA concentration (A) loading exceeded 5.58 wt.\% and parameters $\mathrm{C}$ was at low level $(2 \mathrm{~h})$. This reduction in WCME conversion is due to the increase in the viscosity of reaction mixture which leads to poor 
diffusion of reactants (Dhawane et al., 2016; Laskar et al., 2018a). Betiku et al. noticed similar observation and found that biodiesel yield gets reduced after $3.5 \mathrm{wt} \%$ catalyst loading (Betiku et al., 2016). Conversely, WCME conversion is greatly affected when time (C) is increased keeping A at low level. The conversion was seen to increased up to $3.91 \mathrm{~h}$ after which it decreased steady. The increase in conversion is due to the availability of sufficient time for the active catalyst sites to react. However the fall after $3.91 \mathrm{~h}$ is due to hydrolysis of esters which begins with further increase in reaction time (Balajii and Niju, 2019). It was noticed from the 3-D plot (Fig. 10) that the maximum conversion was seen around 5.58-6.3 wt.\% for parameter A and 3.53- 3.91 h for parameter C. The minimum P-value $(<0.0001)$ obtained by ANOVA (Table 5) is due to the effect of interaction between A and C. This obtained P-value testifies the statistical significance of the parameters.

The effect of parameters B and C on WCME conversion was simulated by keeping constant parameter $\mathrm{C}$ in the middle level as shown in Fig. 10. WCME conversion of $<40 \%$ was noticed at low values of both parameters $\mathrm{B}$ and $\mathrm{C}$ which indicated the need of extra methanol for the reaction to proceed further to completion. This fact is validated by the observed improvement in WCME conversion by increasing parameter B from 4:1 to 6.5:1. Similar observation has also been noticed by Balaji et al. (Balajii and Niju, 2019).

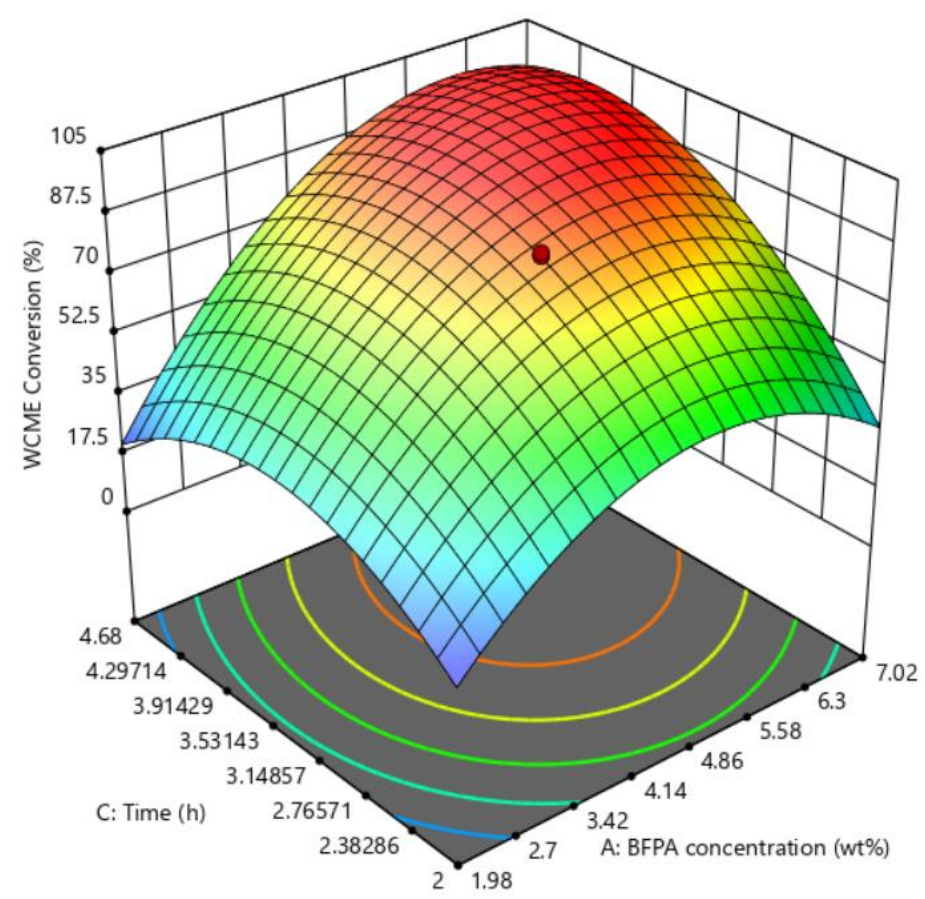

Fig. 9: Interaction effects of time and MAFPA concentration

With the rise in parameter $\mathrm{C}$ keeping $\mathrm{B}$ constant at low values the WCME comnversion increased immensly. This is due to the fact that the active sites of MAFPA got 
more time to come in contact with the reactants resulting in more collisions which eventually enhanced the WCME conversion (Olutoye et al., 2011). The parameter B after 6.86:1 M/O ratio with time $2 \mathrm{~h}$ deteriorated the WCME conversion. With high M/O ratio, reaction mixtures became dilute which decreased the contact between active surfaces of MAFPA and reactants (Mendonça et al., 2019). Similarly at high M/O ratio and time, WCME conversion reduced due to glycerol's affinity to disolve in reaction mixture coupled with dilution of MAFPA concentration in surplus methanol (Balajii and Niju, 2019). From Fig. 10, the maximum conversion was noted in between 6.14:1-6.86:1 $\mathrm{M} / \mathrm{O}$ ratio and 3.53- $3.91 \mathrm{~h}$. The statistical significance is registered since interaction of $\mathrm{M} / \mathrm{O}$ ratio $(\mathrm{B})$ and time (C) yielded pvalue of 0.0002 and high F- value of 46.59. All the plots displayed a drop in WCME conversion when all the parameters were kept at high level.

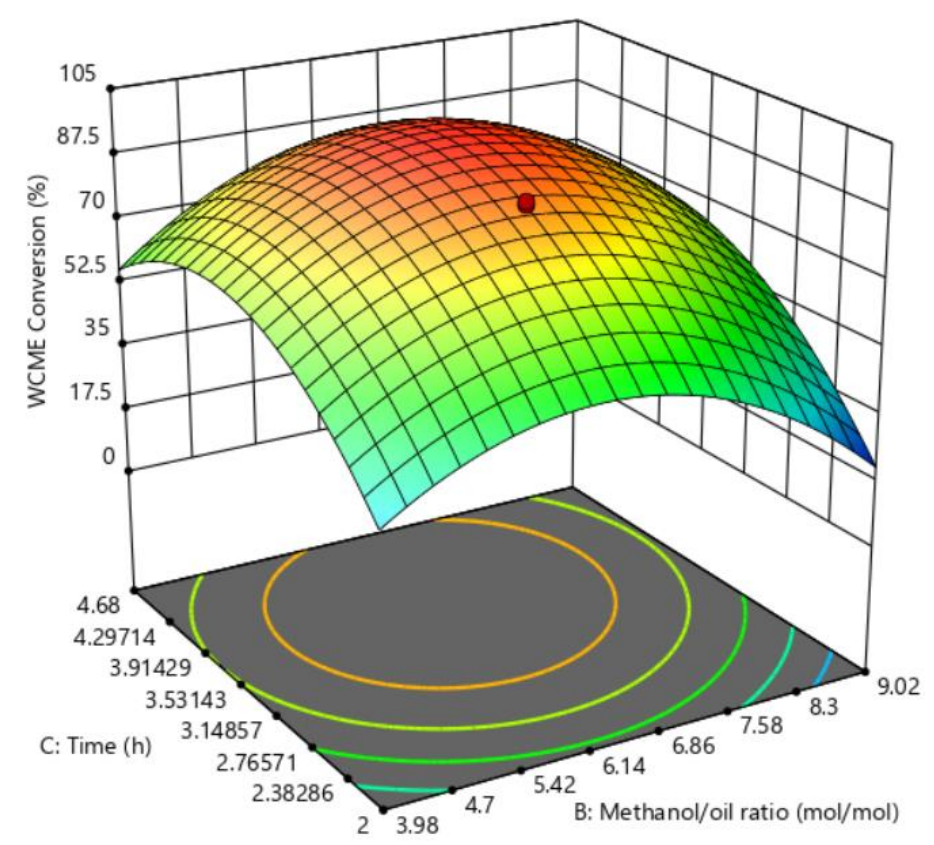

Fig. 10: Interaction effects of time and $M / O$ ratio

\subsection{Optimization of transesterification parameters}

\subsubsection{Using design expert}

In order to obtain the best parameters values accountable for high WCME conversion, numerical method available in Design Expert software is applied and proposed result is presented in Fig. 11. The regression model of numerical method anticipated a highest conversion of $99.99 \%$ with MAFPA concentration of 5.63 wt.\%, M/O molar ratio of 6.24:1 and time of $3.68 \mathrm{~h}$. To validate the proposed result, a proper global optimization of the parameters has been done using PSO in the next section. 

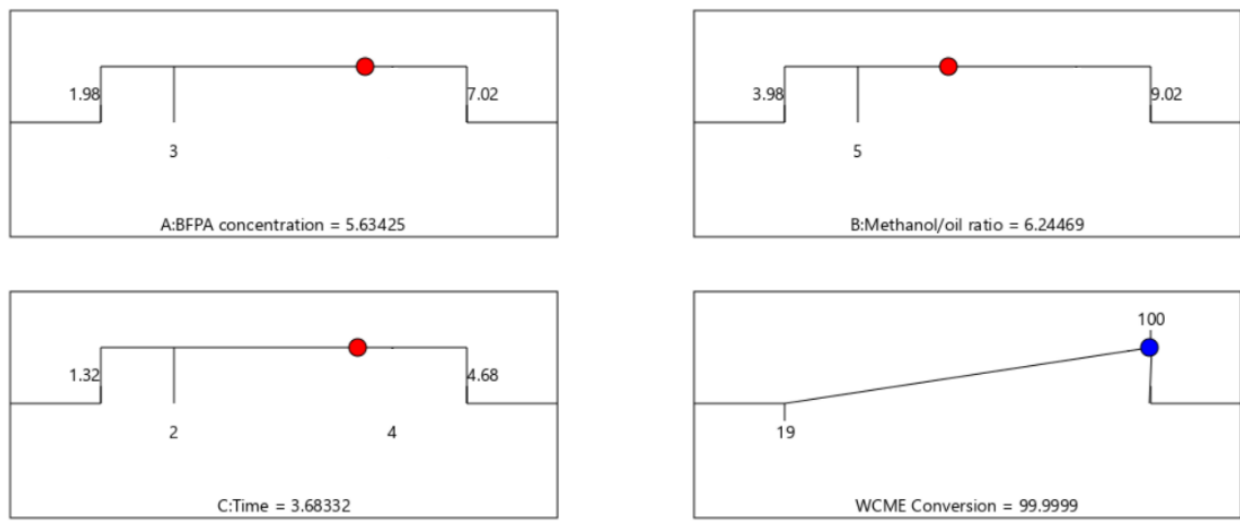

Fig. 11: Optimized operating conditions for WCME conversion

\subsubsection{Using PSO}

The PSO algorithm used in the current study is coded by the authors in MATLAB 2015 and run in a computer having 64-bit processor and 4 GB RAM. The code used a linearly decreasing inertia weight which helps the algorithm to explore the search space in the initial iterations and exploited the promising regions in the layer half of the search. Due to the stochastic nature of the algorithm, the code was run for 25 times and the best values have been reported. The parameters' values have been reported in Table 6 .

Table 6 :Algorithm centric parameters of PSO (Deshamukhya et al., 2020) and their values

\begin{tabular}{ccc}
\hline Algorithms & Parameters & Values \\
\hline PSO & Number of birds & 25 \\
Number of & 100 \\
iterations & \\
$c_{1}$ & 1 \\
$c_{2}$ & 1 \\
$w$ & Linearly decreasing from 0.9 to 0.4
\end{tabular}




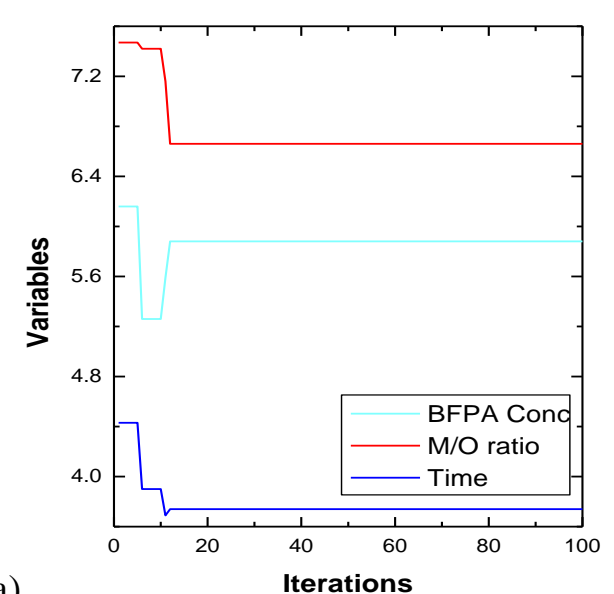

(a)

FIG 12: Convergence plots of (a) variables and (b) WCME yield obtained by PSO

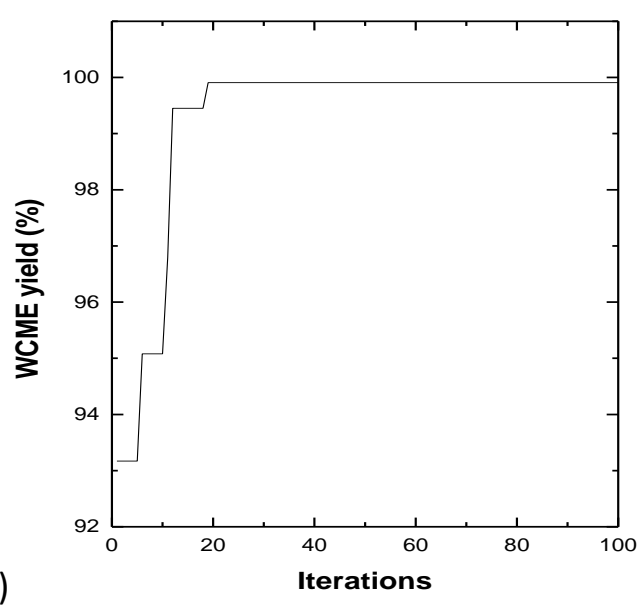

The swarm of 25 particles have converged around $15^{\text {th }}$ iteration. However, the algorithm was run for 100 iterations each time to make sure the particles do not fluctuate to newer points in the domain. From Table 7, it can be seen that the results obtained by PSO and CCD differ by a negligible amount of $0.08 \%$ which authenticates the findings. The transesterification of $\mathrm{WCO}$ is then performed experimentally under optimal conditions obtained from CCD using MAFPA catalyst and a conversion of $98.5 \%$ (using Eq. (1)) has been obtained.

Table 7: Validation of the results obtained by CCD with PSO

\begin{tabular}{ccccc}
\hline Methods & $\begin{array}{c}\text { MAFPA (in } \\
\%)\end{array}$ & M/O & $\begin{array}{c}\text { Time (in } \\
\text { hours) }\end{array}$ & $\begin{array}{c}\text { WCME yield (in } \\
\%)\end{array}$ \\
\hline CCD & 5.63 & $6.24: 1$ & 3.68 & 99.99 \\
PSO & 5.88 & $6.66: 1$ & 3.74 & 99.91 \\
\hline
\end{tabular}

\subsection{Biodiesel charecterisation}

\subsection{1 ${ }^{1} \mathrm{H}$ NMR analysis}

NMR spectrometry was selected to explicate the FAME formation from WCO and the result is displayed in Fig.13. A singlet appearance has been observed at $3.66 \mathrm{ppm}$ due to methoxy protons which confirmed the formation of biodiesel. Another important peak associated with confirmation of SOME formation was observed at $2.29 \mathrm{ppm}$ for $\alpha-\mathrm{CH}_{2}$ protons (Balajii and Niju, 2019; Laskar et al., 2018a). The WCME conversion of $98.5 \%$ was estimated using Eq. 1 for the optimised operating conditions. 


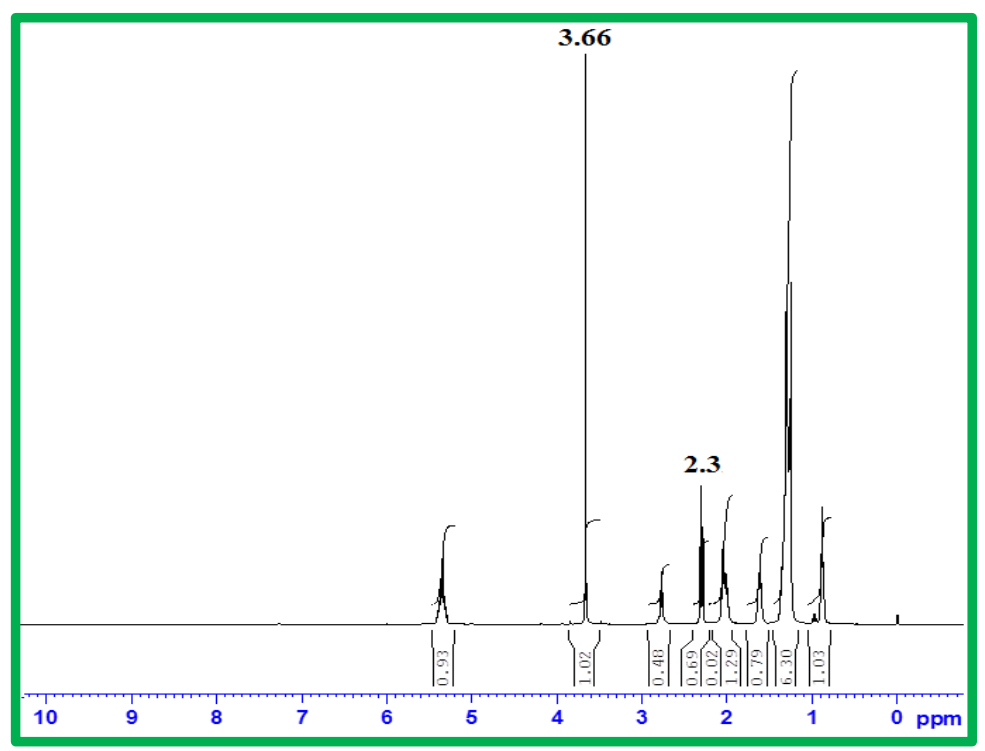

Fig. 13: ${ }^{1} \mathrm{H}$ NMR of soybean oil biodiesel

\subsubsection{GCMS analysis}

The constituents present in the prepared WCME were identified using GCMS analysis and chromatograph of WCME is illustrated in Fig.14. To determine each constituent in percentage, the predetermined area of internal standard (methyl pentadecanoate, C15:0) was equated with the corresponding area of WCME. The identified components of WCME are listed in Table 8.

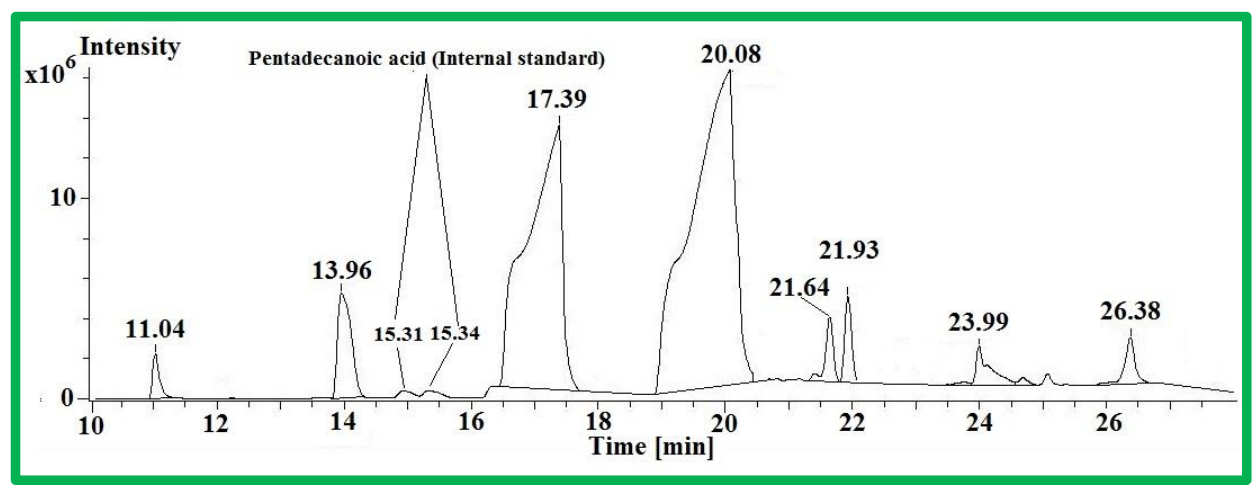

Fig. 14: GC spectra of WCME

Table 8: Chemical composition of WCME

\begin{tabular}{lllll}
\hline Peak & $\begin{array}{l}\text { R.t } \\
\text { No }\end{array}$ & Identified compound & $\begin{array}{l}\text { Corresponding } \\
\text { acids }\end{array}$ & $\begin{array}{l}\text { Quantity } \\
(\%)\end{array}$ \\
\hline 1 & 11.04 & Methyl dodecanoate & C12:0 & 1.16 \\
2 & 13.96 & Methyl tetradecanoate & C14:0 & 5.36
\end{tabular}




\begin{tabular}{lllll}
3 & 17.39 & Methyl hexadecanoate & C16:0 & 34.31 \\
4 & 20.08 & Methyl 11-octadecanoate & C18:1 & 52.3 \\
5 & 21.64 & Methyl-11-ecosenoate & C20:1 & 0.84 \\
6 & 21.93 & Methyl -nonadecanoate & C20:0 & 2.22 \\
7 & 23.99 & Methyl -docosaanoate & C22:0 & 1.97 \\
8 & 26.38 & Methyl tetracosanoate & C 24:0 & 1.81 \\
\hline
\end{tabular}

The principle components present in SOME are methyl- octadecadienoate (52.3\%), Methyl hexadecanoate (34.31 \%), Methyl tetradecanoate (5.36 \%) and Methyl nonadecanoate $(2.22 \%)$. Other components such as Methyl -docosaanoate (1.97\%), Methyl tetracosanoate $(1.81 \%)$, Methyl dodecanoate $(1.16 \%)$ and Methyl-11-ecosenoate $(0.84 \%)$ are present in small amount. The physicochemical properties of WCO and WCME were evaluated and results are compiled in Table 9.

Table 9: Physicochemical properties of WCO and WCME

\begin{tabular}{llll}
\hline Properties & WCO & WCME & ASTM standard \\
\hline Saponification value $(\mathrm{mg} \mathrm{KOH} / \mathrm{g})$ & 184.37 & -- & D5558 \\
Acid value $(\mathrm{mg} \mathrm{KOH} / \mathrm{g})$ & 1.95 & 0.52 & $\mathrm{D} 664$ \\
FFA $(\%)$ & 0.98 & 0.26 & $\mathrm{D} 664$ \\
Kinematic viscosity $\left(\mathrm{cst}\right.$ at $\left.40{ }^{\circ} \mathrm{C}\right)$ & 34.65 & 5.37 & D 445 \\
Density $\left(\mathrm{g} / \mathrm{cm}^{3}\right)$ & 0.924 & 0.865 & D $1448-1972$ \\
Cetane number & -- & 52 & D 6890 \\
Flash point $\left({ }^{\circ} \mathrm{C}\right)$ & 315 & 142 & D 7215 \\
Cloud point $\left({ }^{\circ} \mathrm{C}\right)$ & -5 & 0 & D 97 \\
Pour point $\left({ }^{\circ} \mathrm{C}\right)$ & -7 & -2 & D 2500 \\
Copper strip corrosion & $1(\mathrm{a})$ & $1(\mathrm{a})$ & D 130 \\
\hline
\end{tabular}

\subsection{Catalyst Reusability}

In order to ensure the efficiency of catalyst in retaining the catalytic activity in successive cycles, reusability study has been performed. After the completion of each cycle, the catalyst was reactivated for its application in next cycle. Once the reaction completed, the catalyst was collected through centrifugation, separated from undesirable materials by washing with 
distilled water and acetone followed by drying in an oven for $10 \mathrm{~h}$ at $100{ }^{\circ} \mathrm{C}$. The recover catalyst was tested for the subsequent reaction cycle under the optimal reaction conditions and results are depicted in Fig. 15.

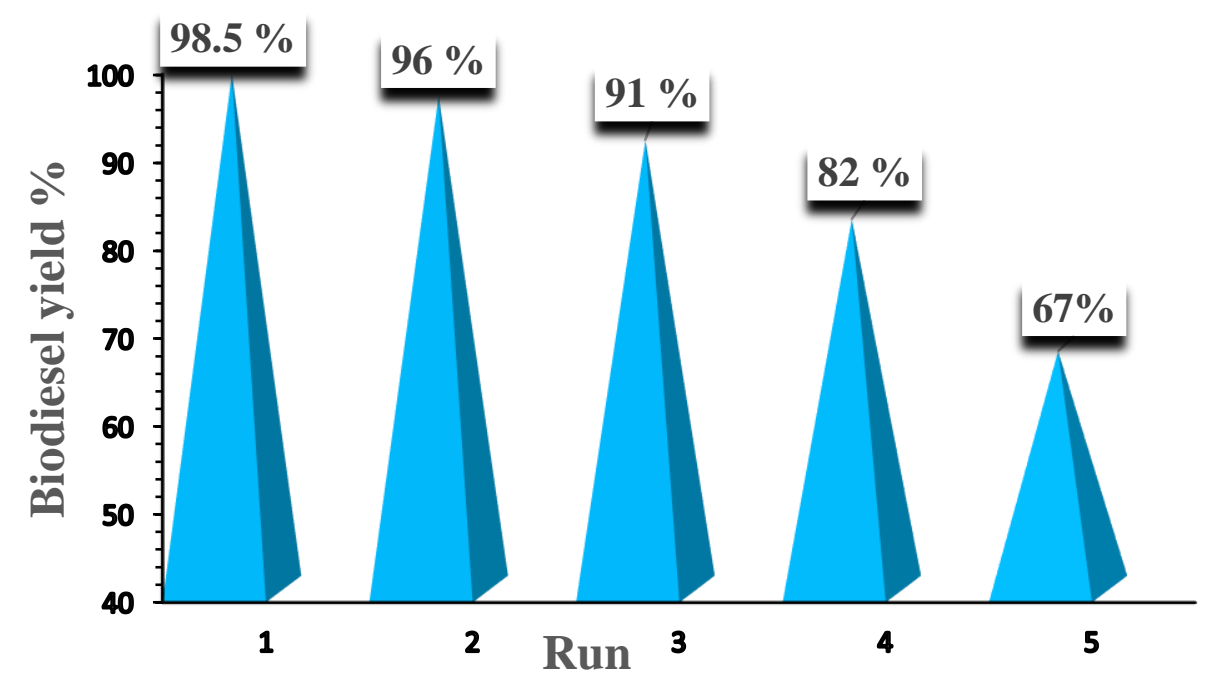

Fig. 15: Reusability of MAFPA catalyst at catalyst concentration $6 \mathrm{wt} \%$, Methanol/oil ratio 6:1 and time $4 \mathrm{~h}$

It has been deduced from the reusability study that a minimal fall in oil conversion to biodiesel yield occurs up to $4^{\text {th }}$ cycle. The oil conversion has abruptly dropped to $67 \%$ in $5^{\text {th }}$ cycle from $82 \%\left(4^{\text {th }}\right.$ cycle). This, rapid downfall of catalytic activity in reaction was probably attributed to leaching of active sites of the presented catalyst. The EDS analysis of spent catalyst (after $5^{\text {th }}$ cycle) clearly confirmed that the concentration of $\mathrm{K}$ significantly drops from 45.44 wt.\% to 21.82 wt.\% (See SI, Fig. S2) which is equivalent to $51.9 \%$ loss in potassium after $5^{\text {th }}$ cycle. The spent catalyst (after $5^{\text {th }}$ cycle) was also analyzed using XPS to identify the remaining elements in the catalyst after its repeated re-use in the reaction. The results of the analysis are listed in supplementary information (SI), Table S1. The potassium percentage was found to fall from $23.5 \mathrm{wt} \%$ (fresh catalyst) to $13.79 \mathrm{wt} \%$ for spent catalyst, which signifies a drop of $41 \mathrm{wt} . \%$. The full scan spectra and core level spectra of C $1 \mathrm{~s}, \mathrm{O} 1 \mathrm{~s}$, and $\mathrm{K} 2 \mathrm{p}$ are presented in SI (Fig. S3). Hence, it is understood from XPS results that potassium ( $\mathrm{K}=23.5 \%$ ) occupies large portion of the fresh catalyst. In reused catalyst (after $4^{\text {th }}$ cycle), $\mathrm{K}$ concentration is quite high compared to other elements. Thus, $\mathrm{K}$ primarily in the form of $\mathrm{K}_{2} \mathrm{O}$ and $\mathrm{K}_{2} \mathrm{CO}_{3}$ takes part in the transesterification reaction. Hence, the decrease in the $\mathrm{K}$ percentage in the catalyst affects the catalytic activity in the reaction to a large extent.

Moreover, the poor performance of the catalyst may also be due to the fact that the MAFPA surface absorbed oil, $\mathrm{CO}_{2}$, moistures, impurities, glycerol and ester during its 
repeated use which resulted in agglomerated and larger particle size than the fresh MAFPA (Sirisomboonchai et al., 2015). A larger particle size resulted in lesser exposed surface area; thereby, reducing the active sites on MAFPA surfaces to interact with the reactant. This, along with leaching of active sites, is probably the reason for significant drop in oil conversion in $5^{\text {th }}$ cycle (Joshi et al., 2015; Lee and Wilson, 2015). This fact may be confirmed from the SEM, TEM and BET analysis of reused catalyst (after $5^{\text {th }}$ cycle). SEM and TEM clearly exhibited agglomerated and larger sizes particles (SI, Fig. S4). A reduction in surface area has seen from the BET analysis of spent catalyst (after $5^{\text {th }}$ cycle). The BET surface area $\left(53.335 \mathrm{~m}^{2} / \mathrm{g}\right)$ and pore volume $\left(0.171 \mathrm{~cm}^{3} / \mathrm{g}\right)$ of reused catalyst has remarkably decreased from the original value obtained for fresh catalyst (Fig. S5). In fresh catalyst only mesoporous structure was observed. However, in pore size distribution of reused catalyst, pores of both micro and meso porous with average diameter of $6.96 \mathrm{~nm}$ have been recorded. The occurrence of these micro pores in reused catalyst may be due to partial blockage of pores.

\section{Conclusion}

This research deals with preparing a novel catalyst from waste banana flower petals in improving room temperature aided transesterification reaction for producing WCME. The parameters of transesterification responsible for shaping WCO into WCME were optimized with CCD of RSM to maximize the conversion. The results were validated with a powerful global metaheuristic optimization technique, Particle Swarm Optimization (PSO), where all the important variables were simultaneously optimized to get a true picture of the fitness landscape. In order to transform waste (banana flower petals) into an ash catalyst, a conventional open burning approach was performed considering its process simplicity and economic benefits. This ash-based catalyst preparation is very economical as the method is devoid of post-functionalization, elevated temperature, high technology, and complex preparation route. The presence of several oxides such as $\mathrm{K}_{2} \mathrm{O}, \mathrm{SiO}_{2}, \mathrm{CaO}, \mathrm{MgO}, \mathrm{MnO}, \mathrm{CuO}$, $\mathrm{SrO}$, etc. in the in the presented catalyst has resulted in high basic strength. In addition, the porous nature and moderate surface area also have boosted the rate of transesterification reaction to produce biodiesel. The basic strength of the catalyst as determined using Hammett indicator lies in between $15<\mathrm{H}_{-}<18.4$. The MAFPA catalyst can be reused upto $4^{\text {th }}$ cycle without any significant drop in its activity. The fall in catalyst activity after the $4^{\text {th }}$ cycle of reused may also be due to leaching of metal oxides coupled with oil, moisture, $\mathrm{CO}_{2}$ and 
impurities absorbed on the MAFPA. The ash catalyst is extremely useful considering some crucial factors such as ease in synthesis, biodegradable, low cost, high reaction activity, biogenic and eco-friendly. These traits make the catalyst a "green and sustainable catalyst" for industrial scale biodiesel production.

\section{Acknowledgement}

The authors gratefully acknowledged to SAIF (NEHU Shillong, IIT Bombay, IIT Delhi and IIT Guwahati) for analysis. IB Laskar acknowledged MHRD, India for providing research fellowship.

\section{References}

Ang, G.T., Ooi, S.N., Tan, K.T., Lee, K.T., Mohamed, A.R., 2015. Optimization and kinetic studies of sea mango (Cerbera odollam) oil for biodiesel production via supercritical reaction. Energy Convers. Manag. 99, 242-251. https://doi.org/10.1016/j.enconman.2015.04.037

Babaki, M., Yousefi, M., Habibi, Z., Mohammadi, M., 2017. Process optimization for biodiesel production from waste cooking oil using multi-enzyme systems through response surface methodology. Renew. Energy 105, 465-472. https://doi.org/10.1016/j.renene.2016.12.086

Balajii, M., Niju, S., 2020. Banana peduncle - A green and renewable heterogeneous base catalyst for biodiesel production from Ceiba pentandra oil. Renew. Energy. https://doi.org/10.1016/j.renene.2019.08.062

Balajii, M., Niju, S., 2019. A novel biobased heterogeneous catalyst derived from Musa acuminata peduncle for biodiesel production - Process optimization using central composite design. Energy Convers. Manag. https://doi.org/10.1016/j.enconman.2019.03.085

Balbaşi, M., Bartan, A., Ar, I., Gürü, M., 2011. Development of low cost heterogeneous catalysts for biodiesel processes. Energy Sources, Part A Recover. Util. Environ. Eff. 33, 1035-1047. https://doi.org/10.1080/15567030903330736

Barekati-Goudarzi, M., Boldor, D., Nde, D.B., 2016. In-situ transesterification of seeds of 
invasive Chinese tallow trees (Triadica sebifera L.) in a microwave batch system (GREEN3) using hexane as co-solvent: Biodiesel production and process optimization. Bioresour. Technol. 201, 97-104. https://doi.org/10.1016/j.biortech.2015.11.028

Betiku, E., Ajala, S.O., 2014. Modeling and optimization of Thevetia peruviana (yellow oleander) oil biodiesel synthesis via Musa paradisiacal (plantain) peels as heterogeneous base catalyst: A case of artificial neural network vs. response surface methodology. Ind. Crops Prod. https://doi.org/10.1016/j.indcrop.2013.12.046

Betiku, E., Akintunde, A.M., Ojumu, T.V., 2016. Banana peels as a biobase catalyst for fatty acid methyl esters production using Napoleon's plume (Bauhinia monandra) seed oil: A process parameters optimization study. Energy. https://doi.org/10.1016/j.energy.2016.02.138

Birla, A., Singh, B., Upadhyay, S.N., Sharma, Y.C., 2012. Kinetics studies of synthesis of biodiesel from waste frying oil using a heterogeneous catalyst derived from snail shell. Bioresour. Technol. 106, 95-100. https://doi.org/10.1016/j.biortech.2011.11.065

Canakci, M., Sanli, H., 2008. Biodiesel production from various feedstocks and their effects on the fuel properties. J. Ind. Microbiol. Biotechnol. 35, 431-441. https://doi.org/10.1007/s10295-008-0337-6

Carrero, A., Vicente, G., Rodríguez, R., Linares, M., Del Peso, G.L., 2011. Hierarchical zeolites as catalysts for biodiesel production from Nannochloropsis microalga oil. Catal. Today 167, 148-153. https://doi.org/10.1016/j.cattod.2010.11.058

Changmai, B., Laskar, I.B., Rokhum, L., 2019a. Microwave-assisted synthesis of glycerol carbonate by the transesterification of glycerol with dimethyl carbonate using Musa acuminata peel ash catalyst. J. Taiwan Inst. Chem. Eng. https://doi.org/10.1016/j.jtice.2019.06.014

Changmai, B., Sudarsanam, P., Rokhum, L., 2019b. Biodiesel production using a renewable mesoporous solid catalyst. Ind. Crops Prod. 111911. https://doi.org/10.1016/j.indcrop.2019.111911 
Chen, G.Y., Shan, R., Shi, J.F., Yan, B.B., 2015. Transesterification of palm oil to biodiesel using rice husk ash-based catalysts. Fuel Process. Technol.

https://doi.org/10.1016/j.fuproc.2015.01.005

Chin, L.H., Hameed, B.H., Ahmad, A.L., 2009. Process Optimization for Biodiesel Production from Waste Cooking Palm Oil (Elaeis guineensis) Using Response Surface Methodology. Energy and Fuels. https://doi.org/10.1021/ef8007954

Chouhan, A.P.S., Sarma, A.K., 2013. Biodiesel production from Jatropha curcas L. oil using Lemna perpusilla Torrey ash as heterogeneous catalyst. Biomass and Bioenergy 55, 386-389. https://doi.org/10.1016/j.biombioe.2013.02.009

Correia, L.M., Saboya, R.M.A., de Sousa Campelo, N., Cecilia, J.A., Rodr??guez-Castell??n, E., Cavalcante, C.L., Vieira, R.S., 2014. Characterization of calcium oxide catalysts from natural sources and their application in the transesterification of sunflower oil. Bioresour. Technol. 151, 207-213. https://doi.org/10.1016/j.biortech.2013.10.046

Da Silva, C.X.A., Gonalves, V.L.C., Mota, C.J.A., 2009. Water-tolerant zeolite catalyst for the acetalisation of glycerol. Green Chem. 11, 38-41. https://doi.org/10.1039/b813564a

Deka, D.C., Basumatary, S., 2011. High quality biodiesel from yellow oleander (Thevetia peruviana) seed oil. Biomass and Bioenergy. https://doi.org/10.1016/j.biombioe.2011.01.007

Deshamukhya, T., Bhanja, D., Nath, S., 2020. Application of metaheuristic algorithms in optimum thermal design analysis of a rectangular porous fin subjected to both insulated and convective tip conditions. Proc. Inst. Mech. Eng. Part A J. Power Energy 0, 1-14. https://doi.org/10.1177/0957650919899559

Dharma, S., Masjuki, H.H., Ong, H.C., Sebayang, A.H., Silitonga, A.S., Kusumo, F., Mahlia, T.M.I., 2016. Optimization of biodiesel production process for mixed Jatropha curcasCeiba pentandra biodiesel using response surface methodology. Energy Convers. Manag. 115, 178-190. https://doi.org/10.1016/j.enconman.2016.02.034

Dhawane, S.H., Kumar, T., Halder, G., 2016. Parametric effects and optimization on 
synthesis of iron (II) doped carbonaceous catalyst for the production of biodiesel. Energy Convers. Manag. 122, 310-320. https://doi.org/10.1016/j.enconman.2016.06.005

Farooq, M., Ramli, A., 2015. Biodiesel production from low FFA waste cooking oil using heterogeneous catalyst derived from chicken bones. Renew. Energy 76, 362-368. https://doi.org/10.1016/j.renene.2014.11.042

Gohain, M., Devi, A., Deka, D., 2017. Musa balbisiana Colla peel as highly effective renewable heterogeneous base catalyst for biodiesel production. Ind. Crops Prod. 109, 8-18. https://doi.org/10.1016/j.indcrop.2017.08.006

Guan, G., Kusakabe, K., Yamasaki, S., 2009. Tri-potassium phosphate as a solid catalyst for biodiesel production from waste cooking oil. Fuel Process. Technol. 90, 520-524. https://doi.org/10.1016/j.fuproc.2009.01.008

Gui, M.M., Lee, K.T., Bhatia, S., 2008. Feasibility of edible oil vs. non-edible oil vs. waste edible oil as biodiesel feedstock. Energy 33, 1646-1653. https://doi.org/10.1016/j.energy.2008.06.002

Jaliliannosrati, H., Amin, N.A.S., Talebian-Kiakalaieh, A., Noshadi, I., 2013. Microwave assisted biodiesel production from Jatropha curcas L. seed by two-step in situ process: Optimization using response surface methodology. Bioresour. Technol. 136, 565-573. https://doi.org/10.1016/j.biortech.2013.02.078

Joshi, G., Rawat, D.S., Lamba, B.Y., Bisht, K.K., Kumar, P., Kumar, N., Kumar, S., 2015. Transesterification of Jatropha and Karanja oils by using waste egg shell derived calcium based mixed metal oxides. Energy Convers. Manag. https://doi.org/10.1016/j.enconman.2015.02.061

Jung, J.M., Oh, J.I., Baek, K., Lee, J., Kwon, E.E., 2018. Biodiesel production from waste cooking oil using biochar derived from chicken manure as a porous media and catalyst. Energy Convers. Manag. 165, 628-633. https://doi.org/10.1016/j.enconman.2018.03.096

Kennedy, J., Eberhart, R.C., 1995. Particle swarm optimization. Proc. ICNN'95 - Int. Conf. Neural Networks, Perth, WA, Aust. IEEE Xplore 4, 1942-1948. 
https://doi.org/10.1109/ICNN.1995.488968

Knothe, G., Kenar, J.A., 2004. Determination of the fatty acid profile by $1 \mathrm{H}-\mathrm{NMR}$ spectroscopy. Eur. J. Lipid Sci. Technol. 106, 88-96. https://doi.org/DOI 10.1002/ejlt.200300880

Kouzu, M., Hidaka, J.S., 2012. Transesterification of vegetable oil into biodiesel catalyzed by CaO: A review. Fuel 93, 1-12. https://doi.org/10.1016/j.fuel.2011.09.015

Kulkarni, M.G., Dalai, A.K., 2006. Waste cooking oil - An economical source for biodiesel: A review. Ind. Eng. Chem. Res. 45, 2901-2913. https://doi.org/10.1021/ie0510526

Laskar, I.B., Rajkumari, K., Gupta, R., Chatterjee, S., Paul, B., Rokhum, L., 2018a. Waste snail shell derived heterogeneous catalyst for biodiesel production by the transesterification of soybean oil. RSC Adv. 8. https://doi.org/10.1039/c8ra02397b

Laskar, I.B., Rajkumari, K., Gupta, R., Rokhum, L., 2018b. Acid-Functionalized Mesoporous Polymer-Catalyzed Acetalization of Glycerol to Solketal, a Potential Fuel Additive under Solvent-Free Conditions. Energy and Fuels 32. https://doi.org/10.1021/acs.energyfuels.8b02948

Laskar, I.B., Rokhum, L., Gupta, R., Chatterjee, S., 2019. Zinc oxide supported silver nanoparticles as a heterogeneous catalyst for production of biodiesel from palm oil. Environ. Prog. Sustain. Energy. https://doi.org/10.1002/ep.13369

Lee, A.F., Wilson, K., 2015. Recent developments in heterogeneous catalysis for the sustainable production of biodiesel. Catal. Today 242, 3-18. https://doi.org/10.1016/j.cattod.2014.03.072

Madhuvilakku, R., Piraman, S., 2013. Biodiesel synthesis by TiO2-ZnO mixed oxide nanocatalyst catalyzed palm oil transesterification process. Bioresour. Technol. 150, 5559. https://doi.org/10.1016/j.biortech.2013.09.087

Mansir, N., Teo, S.H., Rashid, U., Saiman, M.I., Tan, Y.P., Alsultan, G.A., Taufiq-Yap, Y.H., 2018. Modified waste egg shell derived bifunctional catalyst for biodiesel 
production from high FFA waste cooking oil. A review. Renew. Sustain. Energy Rev. 82, 3645-3655. https://doi.org/10.1016/j.rser.2017.10.098

Mendonça, I.M., Paes, O.A.R.L., Maia, P.J.S., Souza, M.P., Almeida, R.A., Silva, C.C., Duvoisin, S., de Freitas, F.A., 2019. New heterogeneous catalyst for biodiesel production from waste tucumã peels (Astrocaryum aculeatum Meyer): Parameters optimization study. Renew. Energy 130, 103-110. https://doi.org/10.1016/j.renene.2018.06.059

Mohapatra, D., Mishra, S., Sutar, N., 2010. Banana and its by-product utilisation: An overview. J. Sci. Ind. Res. (India). 69, 323-329.

Nath, B., Das, B., Kalita, P., Basumatary, S., 2019. Waste to value addition: Utilization of waste Brassica nigra plant derived novel green heterogeneous base catalyst for effective synthesis of biodiesel. J. Clean. Prod. https://doi.org/10.1016/j.jclepro.2019.118112

Nayak, M.G., Vyas, A.P., 2019. Optimization of microwave-assisted biodiesel production from Papaya oil using response surface methodology. Renew. Energy 138, 18-28. https://doi.org/10.1016/j.renene.2019.01.054

Niju, S., Meera Sheriffa Begum, K.M., Anantharaman, N., 2016. Enhancement of biodiesel synthesis over highly active $\mathrm{CaO}$ derived from natural white bivalve clam shell Enhancement of biodiesel synthesis over highly active CaO. Arab. J. Chem. 9, 633-639. https://doi.org/10.1016/j.arabjc.2014.06.006

Olutoye, M.A., Lee, S.C., Hameed, B.H., 2011. Synthesis of fatty acid methyl ester from palm oil (Elaeis guineensis) with $\mathrm{K} \mathrm{y}(\mathrm{MgCa}) 2 \mathrm{xO} 3$ as heterogeneous catalyst. Bioresour. Technol. https://doi.org/10.1016/j.biortech.2011.09.033

Pathak, G., Das, D., Rajkumari, K., Rokhum, L., 2018. Exploiting waste: Towards a sustainable production of biodiesel using: Musa acuminata peel ash as a heterogeneous catalyst. Green Chem. 20, 2365-2373. https://doi.org/10.1039/c8gc00071a

Pathak, G., Rajkumari, K., Rokhum, L., 2019. Wealth from waste:: M. acuminata peel wastederived magnetic nanoparticles as a solid catalyst for the Henry reaction. Nanoscale 
Adv. 1, 1013-1020. https://doi.org/10.1039/c8na00321a

Piker, A., Tabah, B., Perkas, N., Gedanken, A., 2016. A green and low-cost room temperature biodiesel production method from waste oil using egg shells as catalyst. Fuel 182, 34-41. https://doi.org/10.1016/j.fuel.2016.05.078

Putra, M.D., Irawan, C., Udiantoro, Ristianingsih, Y., Nata, I.F., 2018. A cleaner process for biodiesel production from waste cooking oil using waste materials as a heterogeneous catalyst and its kinetic study. J. Clean. Prod. 195, 1249-1258. https://doi.org/10.1016/j.jclepro.2018.06.010

Rabie, A.M., Shaban, M., Abukhadra, M.R., Hosny, R., Ahmed, S.A., Negm, N.A., 2019. Diatomite supported by $\mathrm{CaO} / \mathrm{MgO}$ nanocomposite as heterogeneous catalyst for biodiesel production from waste cooking oil. J. Mol. Liq. 279, 224-231. https://doi.org/10.1016/j.molliq.2019.01.096

Rajkumari, K., Das, D., Pathak, G., Rokhum, L., 2019. Waste-to-useful: A biowaste-derived heterogeneous catalyst for a green and sustainable Henry reaction. New J. Chem. https://doi.org/10.1039/c8nj05029e

Rajkumari, K., Rokhum, L., 2020. A sustainable protocol for production of biodiesel by transesterification of soybean oil using banana trunk ash as a heterogeneous catalyst. Biomass Convers. Biorefinery. https://doi.org/10.1007/s13399-020-00647-8

SathyaSelvabala, V., Selvaraj, D.K., Kalimuthu, J., Periyaraman, P.M., Subramanian, S., 2011. Two-step biodiesel production from Calophyllum inophyllum oil: Optimization of modified $\beta$-zeolite catalyzed pre-treatment. Bioresour. Technol. 102, 1066-1072. https://doi.org/10.1016/j.biortech.2010.08.052

Sharma, M., Khan, A.A., Puri, S.K., Tuli, D.K., 2012. Wood ash as a potential heterogeneous catalyst for biodiesel synthesis. Biomass and Bioenergy. https://doi.org/10.1016/j.biombioe.2012.02.017

Shibasaki-kitakawa, N., Honda, H., Kuribayashi, H., Toda, T., 2007. Biodiesel production using anionic ion-exchange resin as heterogeneous catalyst 98, 416-421. 
https://doi.org/10.1016/j.biortech.2005.12.010

Singh, T.S., Verma, T.N., 2019. Taguchi design approach for extraction of methyl ester from waste cooking oil using synthesized $\mathrm{CaO}$ as heterogeneous catalyst: Response surface methodology optimization. Energy Convers. Manag. 182, 383-397. https://doi.org/10.1016/j.enconman.2018.12.077

Sirisomboonchai, S., Abuduwayiti, M., Guan, G., Samart, C., Abliz, S., Hao, X., Kusakabe, K., Abudula, A., 2015. Biodiesel production from waste cooking oil using calcined scallop shell as catalyst. Energy Convers. Manag. https://doi.org/10.1016/j.enconman.2015.02.044

Tan, Y.H., Abdullah, M.O., Kansedo, J., Mubarak, N.M., Chan, Y.S., Nolasco-Hipolito, C., 2019. Biodiesel production from used cooking oil using green solid catalyst derived from calcined fusion waste chicken and fish bones. Renew. Energy 139, 696-706. https://doi.org/10.1016/j.renene.2019.02.110

Tan, Y.H., Abdullah, M.O., Nolasco-Hipolito, C., Taufiq-Yap, Y.H., 2015. Waste ostrichand chicken-eggshells as heterogeneous base catalyst for biodiesel production from used cooking oil: Catalyst characterization and biodiesel yield performance. Appl. Energy. https://doi.org/10.1016/j.apenergy.2015.09.023

Wang, H., Li, Y., Yu, F., Wang, Q., Xing, B., Li, D., Li, R., 2019. A stable mesoporous super-acid nanocatalyst for eco-friendly synthesis of biodiesel. Chem. Eng. J. 364, 111122. https://doi.org/10.1016/j.cej.2019.01.168

Yatish, K. V., Lalithamba, H.S., Suresh, R., Arun, S.B., Kumar, P.V., 2016. Optimization of scum oil biodiesel production by using response surface methodology. Process Saf. Environ. Prot. 102, 667-672. https://doi.org/10.1016/j.psep.2016.05.026 